\title{
Host-Brucella interactions and the Brucella genome as tools for subunit antigen discovery and immunization against brucellosis
}

\section{Gabriel Gomez ${ }^{1 *}$, Leslie G. Adams ${ }^{1}$, Allison Rice-Ficht ${ }^{1,2}$ and Thomas A. Ficht ${ }^{1}$}

${ }^{1}$ Department of Veterinary Pathobiology, Texas A\&M University, College Station, TX, USA

${ }^{2}$ Department of Cellular and Molecular Medicine, Health Science Center, Texas A\&M University, College Station, TX, USA

\section{Edited by:}

Lisa A. Morici, Tulane University

School of Medicine, USA

\section{Reviewed by:}

John Boyce, Monash University, Australia

Katherine A. Brown, The University of Texas at Austin, USA

\section{*Correspondence:}

Gabriel Gomez, Department of

Veterinary Pathobiology, College of Veterinary Medicine and Biomedical

Sciences, Texas A\&M University, 113 Veterinary Medical Research (VMR) Building, College Station, TX 77843, USA.

e-mail:ggomez@cvm.tamu.edu
Vaccination is the most important approach to counteract infectious diseases. Thus, the development of new and improved vaccines for existing, emerging, and re-emerging diseases is an area of great interest to the scientific community and general public. Traditional approaches to subunit antigen discovery and vaccine development lack consideration for the critical aspects of public safety and activation of relevant protective host immunity. The availability of genomic sequences for pathogenic Brucella spp. and their hosts have led to development of systems-wide analytical tools that have provided a better understanding of host and pathogen physiology while also beginning to unravel the intricacies at the host-pathogen interface. Advances in pathogen biology, host immunology, and host-agent interactions have the potential to serve as a platform for the design and implementation of better-targeted antigen discovery approaches. With emphasis on Brucella spp., we probe the biological aspects of host and pathogen that merit consideration in the targeted design of subunit antigen discovery and vaccine development.

Keywords: intracellular pathogens, vaccines, subunit vaccine, antigen discovery, Brucellosis, reverse vaccinology

\section{INTRODUCTION}

Infectious diseases account for significant human morbidity and mortality on a worldwide basis. Among these, important subsets of infectious diseases are those caused by intracellular bacterial pathogens. Brucella, Ricketssia, Coxiella, Chlamydia, Burkholderia, and Francisella are important disease causing intracellular etiologic agents. These bacterial agents are included in the CDC select agent list due to their highly infectious nature and their potential use in acts of bioterrorism. Diseases such as salmonellosis, listeriosis and shigellosis are a concern as they represent a threat to food safety. Tuberculosis is a disease caused by a non-select intracellular pathogen but afflicts approximately one third of the human population and accounts for $20 \%$ of all human deaths due to infectious diseases (Martin, 2005). The intracellular biology of these agents is the result of extensive and complex interactions with their host that are necessary to establish a niche permissive of pathogen survival and propagation. Despite the risk these diseases represent for public health, there are no licensed vaccines in the United States to counteract many of them. This is a pressing need that is currently being addressed by arduous efforts of the biomedical research community. One of the main focuses of these efforts is to identify new and more effective approaches to discover antigens for immunization formulations and vaccine development. In this review, we describe advances in the field of brucellosis and propose a multistep, antigen discovery approach with the goal of developing vaccines protective against brucellosis and other intracellular pathogen diseases.
Brucella spp. classification is based on host preference and virulence (Cloeckaert et al., 2002). Brucellae pathogens have been isolated from a range of species including: Brucella melitensis (primarily in goats and sheep), Brucella abortus (cattle), Brucella suis (swine), Brucella ovis (sheep), Brucella canis (dogs), Brucella ceti (dolphin, porpoise, and whale), Brucella pinnipedialis (seal), Brucella neotomae (desert wood rat), Brucella microti (common vole), and Brucella inopinata was recently isolated from human patients (Scholz et al., 2010; Atluri et al., 2011). The reason for host preference is not clear but recent reports characterizing alterations in the genome attempts to explain these species-specific observations (Wattam et al., 2009).

The incidence of human brucellosis is strongly dependent on animal disease prevalence. Brucellosis is a disease that results in great economic loss, particularly in the food animal production sector. Intense regional efforts to control and eradicate animal brucellosis have been successful in some areas but in many parts of the world it continues to be an important disease. As a result, brucellosis is amongst the most common zoonotic diseases with a worldwide annual incidence of 500,000 new cases (Franco et al., 2007). Although humans and animals are susceptible to brucellosis, there is variation in the clinical manifestations in different species.

Brucellae are highly infectious to humans with an estimated dose of only 10-100 organisms being sufficient to establish an infection via the aerogenous route (Bossi et al., 2004). In decreasing order of virulence, Brucella melitensis, Brucella suis, and Brucella abortus are the agents most commonly implicated 
in human brucellosis (Bossi et al., 2004; Franco et al., 2007; Lucero et al., 2008). Although horizontal human transmission is possible, the most important source of human brucellosis is respiratory or gastro-intestinal exposure to contaminated animal tissue or unpasteurized milk and dairy food products, respectively (Williams, 1970; Eckman, 1975; Taylor and Perdue, 1989; Chomel et al., 1994; Godfroid et al., 2005; Corbel et al., 2006; Mantur et al., 2007). After breaching mucosal barriers, Brucella spp. infect submucosal or intraepithelial phagocytic cells and subvert intracellular trafficking pathways. This allows Brucella spp. to evade protective mechanisms of host phagocytes to establish an intracellular niche amenable to survival and replication and to provide a means for dissemination. Cell-mediated dissemination to distant organs, especially those of reticulendothelial and reproductive systems, occurs via the circulatory system (PizarroCerda et al., 1998; Adams, 2002; Pappas et al., 2005; Franco et al., 2007). The intracellular nature of Brucella spp. favors survival and persistence by evading host immune surveillance. In up to $30 \%$ of cases, human brucellosis develops to a chronic disease often accompanied by a combination of undulant fever and myriad non-specific symptoms (Atluri et al., 2011; Skendros et al., 2011). Brucellae has been reported to successfully colonize and cause pathological changes in a variety of organs including those of the central nervous, hemolymphatic, digestive, respiratory, reproductive, musculoskeletal, and cardiovascular systems, an aspect that complicates diagnosis and may result in delay of treatment (Franco et al., 2007; Mantur et al., 2007; Glynn and Lynn, 2008; Seleem et al., 2010; Skendros et al., 2011). Even when diagnosed in a timely manner, the recommended treatment for brucellosis consists of prolonged administration of antibiotics that often fails to completely clear the pathogen (Falagas and Bliziotis, 2006; Seleem et al., 2010).

\section{MOLECULAR PATHOGENESIS}

In order to understand the pathomechanisms of infectious diseases with clinical significance in animals and humans we must first understand the biology of these agents, and their hosts, in order to unravel the interactions that occur at the host-agent interface. Furthermore, understanding of these mechanisms is important for the development of new and effective chemotherapeutic and prophylactic measures. Brucella spp. and other intracellular pathogens have acquired mechanisms to evade host innate protective mechanisms to readily gain access to the host intracellular compartment. Once internalized, they evade intracellular protective mechanisms and subsist and multiply free in the cytoplasm or within vacuolar compartments. The organisms within this intracellular niche create a focus of infectious agent that potentially serves as a source for persistent systemic infection and a chronic disease state.

\section{INTERNALIZATION}

Much effort has been spent elucidating the pathogenesis of Brucella spp. Although significant and productive strides have been made since the recognition of human brucellosis in the late 1800 's, there is much we do not yet know about the pathogen. However, recent advances in the field have confirmed that the pathogenesis of brucellosis is based on a dynamic and intricate network of interactions that occur at the host-pathogen interface during the invasion, adaptation and replication phases (Rossetti et al., 2011). Deciphering these complex interactions will aid us in elucidating and manipulating the molecular mechanisms responsible for infection and development of disease (Adams, 2002).

Several bacterial and host molecular components that aid or regulate invasion and affect downstream host-pathogen interactions have been identified; however, the full extent of the molecular components and mechanisms acting on either active bacterial penetration or passive uptake of Brucella spp. are not fully understood. It is well accepted that brucellae can efficiently breach mucosal epithelial barriers and are capable of infecting several professional phagocytic and non-phagocytic mammalian cells (Murphy et al., 2002; Billard et al., 2005; Hernandez-Castro et al., 2008; Watanabe et al., 2008; Garcia Samartino et al., 2010; Velasquez et al., 2012). Furthermore, the internalization of Brucella is a regulated process that involves interactions of surface host and pathogen molecular factors. Accordingly, lipid rafts, complement and Fc receptors are host surface entities for which a role in Brucella spp. internalization has thus far been described (Campbell et al., 1994; Moreno and Moriyon, 2002; Watarai et al., 2002; Pei et al., 2008).

With respect to the pathogen, the outermost component of brucellae is its multifunctional and heterogenous outer membrane (Moriyon and Lopez-Goni, 1998; Jimenez de Bagues et al., 2004; Bos et al., 2007; Martin-Martin et al., 2008; Pasquevich et al., 2009). A major component of the membrane is the LPS, an integral outer membrane molecule with three domains (O-antigen, core oligosaccharide, and lipid A) that has a regulatory role in Brucella spp. internalization (Lapaque et al., 2005). Specifically, the $\mathrm{O}$-antigen not only protects the bacterium from intracellular killing mechanisms but also controls its internalization. Brucellae organisms with defects in the LPS (rough) are internalized at a greater rate (i.e., up to 50 fold) than their counterparts with intact LPS (smooth), but are unsuccessful in preventing fusion of the brucellae-containing vacuole with the lysosome (Porte et al., 2003; Jimenez de Bagues et al., 2004; Pei et al., 2008; Haag et al., 2010). These data suggest that cell internalization of Brucella spp. is an $\mathrm{O}$-antigen dependent selective process with implications for downstream survival and replication (Figure 1). Additionally, it has been demonstrated that $\mathrm{O}$-antigen is associated with a protective effect on Brucella spp. membranes to bactericidal polycations and is necessary for lipidraft dependent uptake (Moriyon and Lopez-Goni, 1998; Watarai et al., 2002; von Bargen et al., 2012). However, recent reports suggest that additional bacterial factors also present in rough Brucella spp. organisms may interact with and mediate lipid raft-dependent uptake (Martin-Martin et al., 2010). These data suggest that while rough organisms may be internalized by lipid raft-dependent and independent mechanisms, smooth brucellae are mostly internalized via lipid raft-dependent mechanisms, perhaps explaining the higher uptake rates observed with rough organisms.

A role in internalization has also been described for brucellae outer membrane proteins. A putative role for outer membrane proteins in internalization is suggested by impaired uptake of 


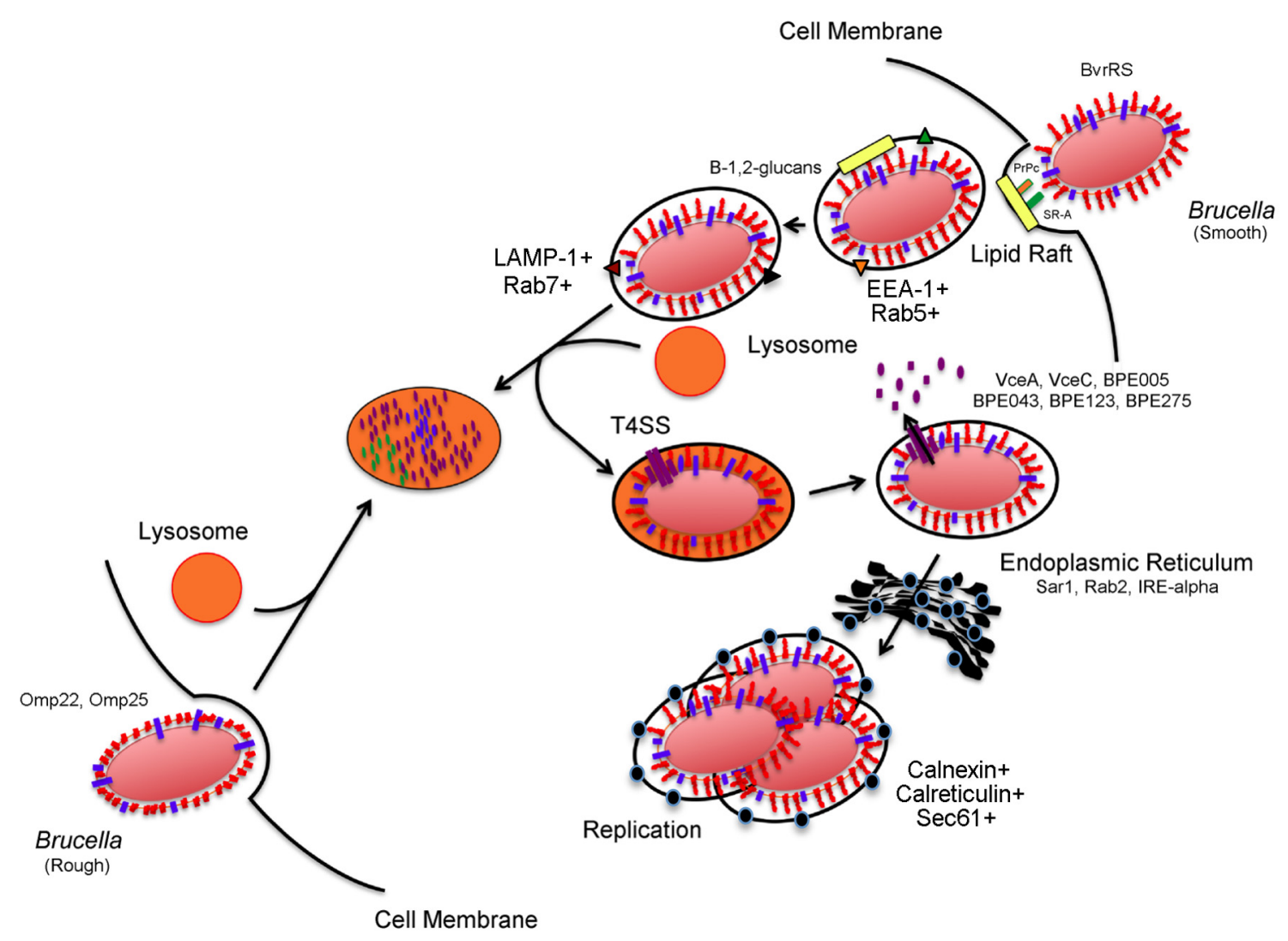

FIGURE 1 | Brucella invasion and intracellular trafficking in host mammalian cells. Smooth Brucella is internalized in a vacuole following interactions with host cell lipid rafts, PrPc, and SR-A. Brucella derived $\beta$-1,2-glucans act by remodeling surface vacuolar lipid-rich domains. The vacuole then fuses transiently with host cell lysosomes for replicationcompetent bacteria. These transient interactions lead to activation of acid-dependent genes, including type 4 secretion system. Type 4 secretion system substrate proteins are translocated to the cytosol of the host cell where they purportedly act to support trafficking and interactions with the endoplasmic reticulum in order to reach the replicative vacuole. In contrast, internalization and intracellular trafficking of rough Brucella is poorly characterized but a role for Brucella Omp22 and Omp25 has been demonstrated. The events that occur after internalization are not clear but ultimately lead to lysosomal degradation.
Brucella spp. with inactivation of the two-component system (TCS), BvrRS. The BvrRS TCS is a sensory transduction bacterial system that is necessary for full expression of various outer membrane proteins (Sola-Landa et al., 1998; Guzman-Verri et al., 2002; Lamontagne et al., 2007; Viadas et al., 2010). Among those, Omp22 and Omp25 are two membrane proteins for which expression is BvrRS dependent. Targeted inactivation of genes omp22 and omp25 impaired internalization of rough B. ovis but not B. abortus (Manterola et al., 2007; Martin-Martin et al., 2008). The basis for these findings is unclear, but suggested explanations range from functional redundancy in the outer membrane to a greater role for LPS in smooth agent internalization and physical obstruction due to LPS-shielding of outer membrane proteins.

Recent reports have identified additional proteins with a role in Brucella spp. adhesion and internalization (Castaneda-Roldan et al., 2006; Hernandez-Castro et al., 2008; Martin-Martin et al., 2008; Czibener and Ugalde, 2012; Posadas et al., 2012). The encoding genes or their protein products have homology to adhesin or invasion factors present in other pathogens including Bartonella bacilliformis (BMEI0216), Salmonella enterica (SP41,
BmaC), and enterohemorrhagic E. coli (Bab1_2009) (CastanedaRoldan et al., 2006; Hernandez-Castro et al., 2008; Czibener and Ugalde, 2012; Posadas et al., 2012). Evidence for the involvement of several host and pathogen components in cell internalization of brucellae coupled with poor mechanistic understanding of the process is a reflection of the intricacies and interdependency acting at the host-agent interface.

\section{INTRACELLULAR TRAFFICKING AND REPLICATION}

Following internalization, intracellular bacterial pathogens are confronted with a variety of harsh conditions within the host cell and with which they must cope and adapt in order to survive. Their ability to adapt by evading, resisting or subverting intracellular host protective mechanisms is dictated by structural components or elaboration of virulence factors that promote survival, replication, persistence, and systemic dissemination as necessary events to cause disease. Collectively, there are a variety of mechanisms that intracellular pathogens have acquired through evolutionary pressure to establish productive intracellular infections. One of the main intracellular host protective mechanisms is degradation of pathogens within lysosomal 
compartments. Intracellular pathogens have acquired strategies to avoid the killing mechanisms of host cells by avoiding lysosomal bactericidal contents through escape to the cytoplasm prior to fusion of phagosome with the lysosome (i.e., Francisella, Shigella, Listeria, Ricketssia), delay, or arrest of phagosome maturation [i.e., Mycobacterium (early endosome), Salmonella (late endosome)], modulation of vacuolar intracellular trafficking pathways so as to permit interactions with host organelles critical for the establishment of a replicative niche (i.e., Legionella) or resistance to killing by lysosomal contents, as is the case for C. burnetii (Starr et al., 2008; Cossart and Roy, 2010; Alix et al., 2011).

Similar to other intracellular pathogens, the complexity of Brucella spp. pathogenesis is demonstrated by its ability to resist intracellular killing mechanisms and reach a membrane-bound replicative-competent niche inside host cells (Figure 1). Brucella spp. are internalized in a lipid-raft containing vacuole that acquires EEA-1 and Rab5 antigens following interactions with the endocytic pathway (von Bargen et al., 2012). The surface cholesterol-rich lipid rafts are then modified by brucellae-derived $\beta$-1,2-glucans (Figure 1) as a necessary step for further maturation of the vacuole (Briones et al., 2001; Roset et al., 2004; von Bargen et al., 2012). As maturation continues, early markers on the Brucella-containing vacuole (BCV) are replaced with late endocytic markers LAMP-1 and Rab7 following interactions with late endosomal compartments. These transient interactions between BCV and late endosomes/lysosomes are controlled to allow vacuolar acidification and transcription of acid-dependent bacterial factors (i.e., virB) but prevent vacuolar inclusion of the proteolytic enzyme, cathepsin D (Boschiroli et al., 2002; von Bargen et al., 2012). The virB operon encodes a membraneassociated type IV secretion system (T4SS) used for the secretion of putative bacterial factors (Figure 1) believed to act to modulate the host cell response to support maturation of the BCV (Boschiroli et al., 2002). Although the presence of these effector proteins was only speculative for years, recent research efforts have revealed the identity of several of these T4SS substrate proteins (Figure 1) including VceA, VceC, BPE005, BPE043, BPE123, and BPE275 (de Jong et al., 2008; Marchesini et al., 2011). Nonetheless, the function of these recently identified substrate proteins remains, for the most part, undefined. Ongoing research is focused on the identification of additional effectors and their functions in an effort to understand the precise role that the T4SS and its substrate molecules play in the maturation of the BCV and establishment of the replicative niche (O'Callaghan et al., 1999; Hong et al., 2000; Gorvel and Moreno, 2002; Celli et al., 2003; den Hartigh et al., 2008; Nijskens et al., 2008). After BCV acidification, the vacuole interacts with the ER via Sar1, Rab2, and IRE- $\alpha$ dependent mechanisms (Celli et al., 2005; Qin et al., 2008; Fugier et al., 2009). These interactions lead to BCV acquisition of ER-specific markers that include calreticulin, calnexin, and Sec61 (von Bargen et al., 2012). Furthermore, brucellae replication only occurs after the BCV interacts with the ER (Starr et al., 2012; von Bargen et al., 2012). Although we have a general understanding of the series of events leading up to Brucella spp. intracellular replication, the post-replicative events are less clear. Bacterial exit from infected cells is required for intercellular and inter-host propagation (Hybiske and Stephens, 2008). A model consisting of smooth dissociation, intracellular rough replication, bacterial-induced cytotoxicity, and pathogen release has been suggested (Turse et al., 2011). Recently, an egress model where the replicative $\mathrm{BCV}$ undergoes further maturation, gains autophagic features and exits as a membrane-bound particle, was reported; however, re-infection of neighboring cells was only demonstrated in human epithelial cells (HeLa) and not the macrophage, the cell type believed to be the major site of Brucella spp. replication (David, 2012; Starr et al., 2012).

If the host is permissible to Brucella spp. infection then survival, replication and egress results from the ability of the pathogen to concurrently alter the function of multiple host systems. Indeed, active manipulation of host immune response to promote its survival is a fundamental aspect of brucellosis. Evasion of intracellular killing mechanisms affords brucellae the ability to localize within a sub-cellular compartment that favors intracellular replication. Understanding the details and applicable mechanisms of pathogen biology is expected to shed light on the identification of treatment options (Alix et al., 2011). Alterations in intracellular trafficking resulting from host-agent interactions at different stages of the Brucella spp. life cycle may be expected to reveal the identity of molecular components or pathways that play an important role in the pathogenesis of the agent (Eriksson et al., 2003; Lucchini et al., 2005; Waddell and Butcher, 2007; Fontan et al., 2008; Wehrly et al., 2009; Fukuto et al., 2010; Rossetti et al., 2011; Pruneau et al., 2012). Most importantly, it is in this intracellular voyage that brucellae actively produce and secrete known and putative molecular effectors that are presumed to aid in the establishment of a replicative niche (Figure 1). Previous studies reveal that known virulence factors such as the $\operatorname{vir} B$ operon, $v j b R$, and Omp25 are upregulated in the intracellular stage of infection (Boschiroli et al., 2002; Wang et al., 2009). Global transcriptional analysis of the intracellular pathogen Francisella tularensis in mouse macrophages revealed that greater than $25 \%$ of the genes over-expressed in the intracellular phase had been previously demonstrated to have a role in replication or virulence of the pathogen (Wehrly et al., 2009). This finding is relevant to vaccine antigen discovery and vaccine development based on the assumption that virulence factors critical to the establishment of infection are less likely to mutate, their expression during infection is necessary, and, hence, may represent good vaccine candidates.

\section{HOST PROTECTIVE IMMUNO-MECHANISMS CELL-MEDIATED IMMUNITY}

Host immunity is divided into innate and adaptive immune responses. Due to the chronic nature of many diseases caused by intracellular pathogens, an effective adaptive response is necessary to control disease. Although several components of the immune system contribute to protection against intracellular pathogens, a cell-mediated immune response has been demonstrated to be critical for protection against Brucella and other intracellular pathogens such as Chlamydia, Francisella, and Mycobacterium (Kamath et al., 2009; Shannon and Heinzen, 2009; Karunakaran et al., 2010; Plotkin, 2010). Macrophages and T-cells play crucial roles in protection. Helper T-cell mediated protection is 
primarily associated with a Th1 T-cell response and persistence (i.e., chronic brucellosis) with a Th2 response (Golding et al., 2001; Giambartolomei et al., 2002; Yingst and Hoover, 2003; Rafiei et al., 2006; Skendros et al., 2007, 2011; Titball, 2008; Perkins et al., 2010). More specifically, studies have demonstrated protective contributions for IFN- $\gamma$, IL-12, and TNF- $\alpha$ against brucellosis (Zhan and Cheers, 1995; Zhan et al., 1996; Murphy et al., 2001; Baldwin and Parent, 2002; Brandao et al., 2012). In addition to the Th1 response, $\mathrm{CD}^{+} \mathrm{T}$ cells also contribute to protection as mice deficient in MHCI presentation fail to control Brucella spp. infection (Oliveira and Splitter, 1995). Protection elicited by passive transfer of $\mathrm{CD}^{+}{ }^{+}$and $\mathrm{CD} 8^{+} \mathrm{T}$ cell subsets corroborate these findings and highlight the importance of $\mathrm{T}$ cell cytotoxicity and T-cell driven cytokine-mediated orchestration of the immune response in protection against brucellosis (Araya et al., 1989). The function of dendritic cells in innate and adaptive immunity and their presence at mucosal surfaces makes their study in brucellosis important (Iwasaki, 2007). Dendritic cells have been demonstrated to be permissive of brucellae infection and replication (Billard et al., 2005; Bosio and Dow, 2005). The role of dendritic cells in protection against brucellosis is not completely understood; however, brucellae have been demonstrated to regulate the response of dendritic cells as detailed below (Billard et al., 2005; Iwasaki, 2007). The $\gamma \delta$ T-cells may also have a role in the control of brucellosis; however, the precise mechanism for this protection is undefined (Bessoles et al., 2011; Skyberg et al., 2011). Lastly, natural killer cells have cell cytotoxic capabilities and are able to secrete IFN- $\gamma$, but a direct role for this cell type in the control of acute brucellosis is not clear (Fernandes et al., 1995; Gao et al., 2011; Vivier et al., 2011). Collectively, these data support a pivotal role for $\mathrm{T}$ cell-mediated immunity in protection against brucellosis. Also, these findings support the assumption that $\mathrm{T}$ cell immunity is the single most important response mediating protection from brucellosis (Araya et al., 1989; Elzer et al., 1994; Hoffmann and Houle, 1995; Ko and Splitter, 2003).

\section{HUMORAL IMMUNITY}

The contributory role of antibody to protection against brucellae is less defined than the role of T-cell immunity; however, precise protective mechanisms of humoral immunity against intracellular pathogens may rely on a focused combination of factors that include antibody isotype and function. Protection studies with animal models deficient in B-cell function indicate that this cell type is not necessary for protection against primary infection, yet passive transfer of antibodies from immunized or exposed animals confer protection on naïve animals against brucellosis (Araya et al., 1989; Casadevall and Pirofski, 2006; Goenka et al., 2011). The results suggest that while antibodies have a protective role against re-infection with Brucella spp., similar to Francisella spp. and Listeria spp., their role in protection against primary infection is less explicit (Casadevall and Pirofski, 2006). These data further imply that innate or alternate immuno-protective mechanisms that precede development of humoral immunity are sufficient to control primary infection and the synergistic and/or inhibitory contributions of specific antibodies need to be further explored (Araya et al., 1989; Casadevall and Pirofski, 2006; Titball, 2008; Shannon and Heinzen, 2009; Goenka et al.,
2011). While antibodies may be protective against secondary exposure, this protective effect is not always apparent in passive immunity transfer studies suggesting a synergistic, rather than an absolute, protective role for humoral immunity. The basis of these findings may aid in understanding antibody immunoprotective mechanisms. This knowledge will aid in understanding the specific mechanisms that are relevant to protection against Brucella spp. and shed light onto the pathogen-specific design and development of therapeutic and prophylactic measures.

\section{IMMUNOPATHOLOGY}

Intracellular pathogens have strategies or contain structural components to evade and remain undetected by the host immune system. Under evolutionary pressure, Brucella spp. have developed elaborate and sophisticated survival-promoting mechanisms en route to its establishment as an important pathogen of mammals. These mechanisms endow brucellae with the ability to complete its life cycle in a protected, intracellular, vacuolar compartment. This is evidenced by its capability to manipulate and evade innate and adaptive immunity and other host protective mechanisms through structural component and secreted soluble factor functionality (Barquero-Calvo et al., 2009). Among these, the TcpB molecule is a multifunctional soluble Brucella-derived factor that alters cytoskeleton function, inhibits dendritic cell maturation and disrupts the MyD88 signaling pathway (Salcedo et al., 2008; Radhakrishnan et al., 2009, 2011; Sengupta et al., 2010; Chaudhary et al., 2012). A recent report also attributes TcpB an inhibitory function on cytotoxic T-cells during chronic brucellosis (Durward et al., 2012). Another important molecule which effects the immune system is PrpA. PrpA is a Brucelladerived B-cell mitogen that supports $\mathrm{B}$ cell secretion of the immuno-suppressive cytokine, IL-10 (Spera et al., 2006). This study is in line with the recent finding that B-cells promote brucellae colonization in the mouse (Goenka et al., 2011). The LPS is also a multifunctional, Brucella-derived factor with immunoregulatory capabilities. Specifically, Brucella spp. LPS has weak endotoxin (immunostimulatory) properties, protects from complement, and controls antigen presentation through formation of persistent LPS-MHC II complexes (Lapaque et al., 2006; Barrionuevo et al., 2008). Several outer membrane proteins have also been demonstrated to support Brucella spp. infection and survival. Brucellae Omp25 regulates TNF- $\alpha$ secretion and prevents apoptosis of macrophages (Gross et al., 2000; Jubier-Maurin et al., 2001; Billard et al., 2007). Anti-apoptotic properties have been demonstrated for the Omp2b porin in macrophages and yeast (He et al., 2006; Laloux et al., 2010). Interestingly, recent reports describe apoptosis of $B$. abortus infected T-lymphocytes and astrocytes (Garcia Samartino et al., 2010; Velasquez et al., 2012). The basis for this selectivity is not clear but the inherent cellular role in promoting brucellosis may be important.

\section{IMMUNIZATION APPROACHES}

Vaccination is the most efficient and inexpensive method to counteract infectious diseases (Oyewumi et al., 2010). Historically, vaccinology has relied on immunization with live-attenuated organisms or subunit antigens as two of the main approaches to elicit host immunoprotection against infectious agents. However, 
the success of the immunization approach used against any given pathogen is influenced by multiple factors including pathogen biology, safety, and acceptable levels of protection.

\section{LIVE ATTENUATED VACCINATION}

Although not always the best option from a biosafety standpoint, live-attenuated vaccination to combat disease caused by intracellular infectious agents is the approach that, in most cases, confers the highest degree and longest duration of protection (de Veer and Meeusen, 2011; Levitz and Golenbock, 2012). The superior protective efficacy of live attenuated vaccines against intracellular pathogens relies in part on their ability to elicit robust cellmediated immune responses (Seder and Hill, 2000; Titball, 2008). Accordingly, protective vaccines exist for Brucella spp. and other intracellular pathogens but aspects such as residual virulence, hypersensitivity, and lack of protective efficacy across age groups makes them unfit for immunization of humans and, therefore, many have failed to meet approval standards for human use in the United States (Blasco and Diaz, 1993; Schurig et al., 2002; Waag et al., 2002; Ashford et al., 2004; Martin, 2005; Wallach et al., 2008; Rockx-Brouwer et al., 2012). Accordingly, intense research efforts have been placed on identifying live-attenuated vaccines directed at brucellae with an acceptable combination of safety and protective properties (Titball, 2008; Ficht et al., 2009). For instance, identification of virulence-related Brucella spp. genes identified via high-throughput mutagenesis studies has resulted in several promising vaccine candidates that are currently in various stages of development (Wu et al., 2006; Ficht et al., 2009; Perkins et al., 2010). Even though live-attenuated organisms provide adequate levels and long-lasting protection, there are concerns associated with the production, stability, and administration of such vaccines (Levitz and Golenbock, 2012). Manipulation and production of live attenuated vaccine strains often necessitate stringent bio-containment. Additionally, risk for reversion to virulence exists and differentiation between exposed and immunized subjects can be challenging and complicate immuno-surveillance efforts. Lastly, there is an ever-present risk of disease in both healthy and the ever-growing population of immune-compromised subjects (Frey, 2007; Chen et al., 2010; Oyewumi et al., 2010).

\section{SUBUNIT VACCINATION}

In efforts to address concerns associated with live-attenuated vaccination, subunit vaccinology is increasingly gaining support as an alternative approach. However, there are many challenges associated with the development of a protective subunit vaccine against Brucella spp. One of the major impediments to progress in this field can be attributed to the difficulty involved in the identification of protective antigens. Second, delivery of soluble subunit antigen primarily targets a humoral immune response as opposed to the crucial cell-mediated immunity needed to protect against Brucella spp.; however, recent developments in delivery of antigen are designed to address these concerns. Lastly, it is unlikely that protection resulting from subunit vaccination against Brucella spp. will depend on a single antigen. An approach to identify antigens that act synergistically to elicit protective immunity must be considered (Titball, 2008; Plotkin, 2010).
Traditional approaches to subunit vaccine development, such as those based on protective efficacy of bacterial fractions with subsequent identification of specific protective antigens, and the use of serology to identify immuno-dominant antigens, has been a common practice (Rappuoli, 2000; Chen et al., 2011). These methods can be tedious and expensive and often give an unsatisfactory outcome. As a result, these approaches have led to the identification of several subunit antigens that elicit marginal or variable levels of protection against brucellosis and which seldom approach the levels of protection elicited by liveattenuated vaccination (Corbel, 1976; Tabatabai and Pugh, 1994; Oliveira and Splitter, 1996; Al-Mariri et al., 2001; Velikovsky et al., 2003; Ashford et al., 2004; Cassataro et al., 2005, 2007; Martin, 2005; Pakzad et al., 2009; Pasquevich et al., 2009). The limited success of this approach and advances in the understanding of host-Brucella spp. interactions has triggered the search for more efficient approaches to antigen discovery and vaccine development.

In the development of subunit vaccines, antigen selection and delivery platform are two key components that merit careful consideration (de Veer and Meeusen, 2011; Levitz and Golenbock, 2012). Significant advances in the fields of immunology, hostagent interactions, microbiology, and bioinformatics have provided insight for the strategic design of targeted tools with protective antigen identification capabilities

\section{ANTIGEN SELECTION}

In the wake of emerging and re-emerging infectious diseases and bioterrorist threats, the need for protective vaccines approved for human use is a priority of research on agents such as Brucella spp. in the United States. To this end, a clear understanding of the molecular interactions between Brucella spp. and the host and the identification of antigenic determinants that stimulate protective host immune responses are fundamental and vital pieces of information that need to be considered. However, the development of a vaccine is further complicated by the peculiarity of Brucella spp. in that it lacks many of the classical virulence factors and has specific mechanisms to counteract host protective mechanisms in order to promote its persistence (Atluri et al., 2011).

One important deterrent to the advancement of subunit vaccine development is the historically ineffective manner of antigen discovery. The identification of immunogenic proteins based solely on humoral immunity is a method that is often suggested or experimentally explored, but this approach undermines or does not always correlate with immune responses determined to have clear relevance to protection against Brucella spp. and other intracellular pathogens, i.e., T cell immunity (Rappuoli, 2000; Liang et al., 2010; Chen et al., 2011; Zhao et al., 2011). The availability of complete genomic sequences for many brucellae and their hosts has made the study of functional genomics, proteomics, and immunomics in the context of host-brucellae interactions possible.

The results obtained from these comprehensive experiments have started to yield data that will increase the understanding of not only the pathogenesis of disease but will also aid in characterizing molecule-specific immunogenicity. Notably, the availability of genomic sequences has led to the development 
of algorithms for the in silico prediction of proteins with desirable structural, (i.e., outer membrane proteins), functional (i.e., adhesin), and antigenic (B cell and $\mathrm{T}$ cell epitopes) determinants (Figure 2). Following from these predictions, each protein can be expressed and tested for immunogenic and protective potential, in an approach known as reverse vaccinology (Rappuoli, 2000; Sette and Rappuoli, 2010). Taking into consideration host protective mechanisms, antigen selection via the reverse vaccinology approach can be tailored to identify antigens that contain a combination of antigenic determinants and functional, conserved, and structural properties (He et al., 2010). In its nascent stage, the use of reverse vaccinology has yielded promising results and progress is being made toward the development of vaccines against several pathogens (Sette and Rappuoli, 2010; Bagnoli et al., 2011). Additionally, this approach is often used in an effort to narrow the number of candidate antigens to a working pool for validation and evaluation. Specifically, reverse vaccinology has aided in the identification of antigens that have protective antigenic determinants from various intracellular pathogens including Chlamydia, Ehrlichia, Francisella, Mycobacterium, and may represent a viable approach to the identification of antigens for immunization against brucellosis (McMurry et al., 2007; Finco et al., 2011; Zvi et al., 2011; Liebenberg et al., 2012; Sundaramurthi et al., 2012).

In addition, availability of genomic sequences has led to the development of whole proteome assays that have been used to determine antigen-specific antibody responses against Brucella spp. (Liang et al., 2010). A clear advantage of these assays is that they will aid in overcoming some limitations of traditional assays such as $2 \mathrm{D}$ gels, which are based on total bacterial lysates and its signal is dependent on the quantity of antigen in the preparation. While this approach will aid in screening immunodominant antigens that have potential vaccinogen value, this approach must be used as an ancillary rather than the sole criterion for antigen selection as humoral immunity does not always correlate with the more protective responses as described above.

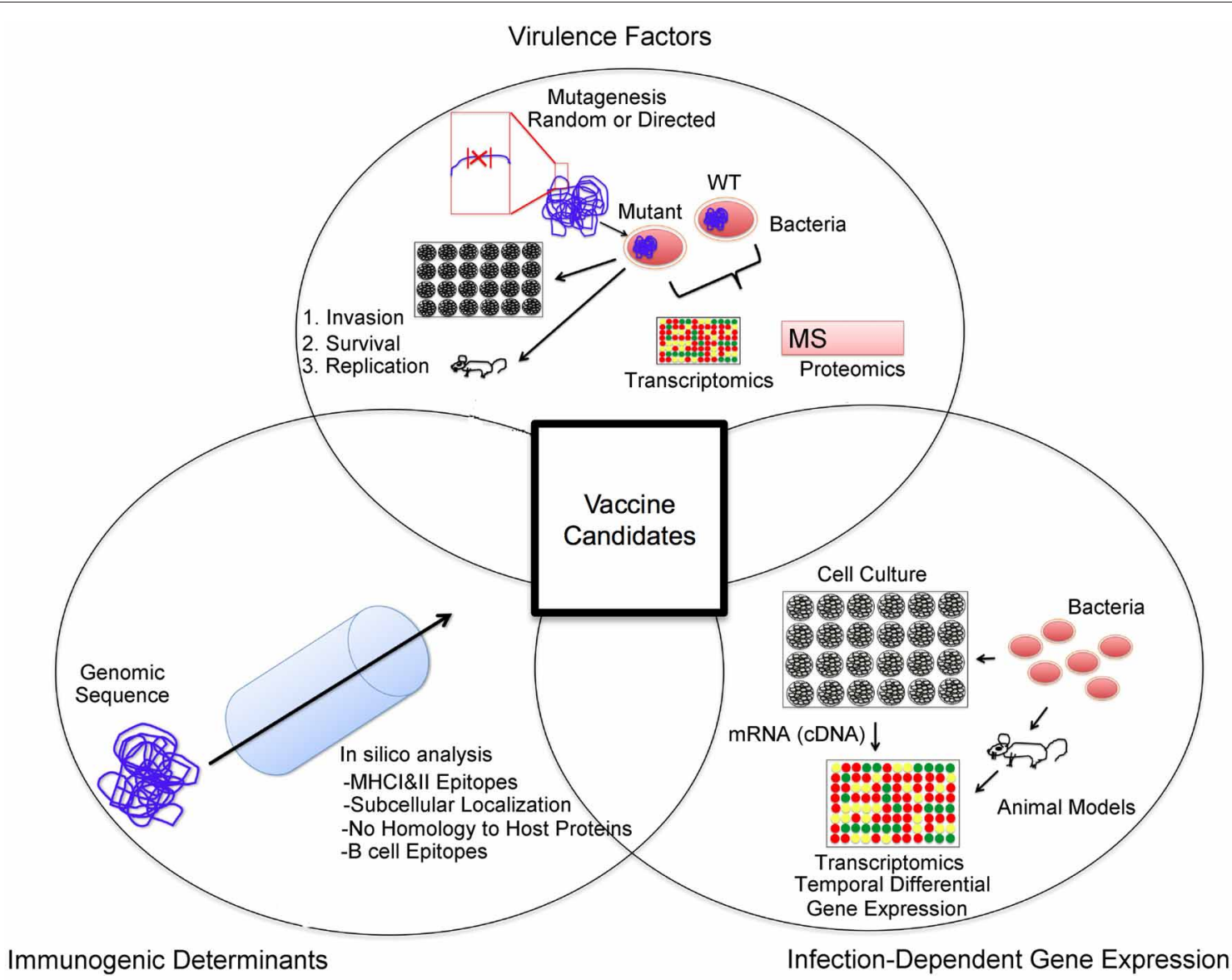

FIGURE 2 | Vaccine candidate selection approach. An important aspect of a vaccine candidate is antigenicity. In silico analysis of available genomic sequences can aid in the selection of open reading frames that code for desired properties such as T and B cell epitopes, subcellular localization (i.e., outer membrane proteins), and a lack of homology to host proteins. Secondly, antigens with evidence for a role in pathogenesis are often targeted in the identification of vaccine candidates. Identification of factors important for invasion, survival, and replication can be performed via mutagenesis studies in the mouse or cell culture systems. Additionally, comparative transcriptomic and proteomic studies of wild type and mutant pathogen strains can be carried out to identify potential virulence factors. Lastly, the priming of an immune response to a specific antigen relies on its availability. In order to identify antigenic targets present during infection, infection-dependent gene expression studies may reveal suitable targets. 
In addition, knowledge of the precise brucellae-specific protective mechanisms of humoral immunity (i.e., antibody isotype) may aid in further focusing selection on the most relevant targets.

One other important aspect of infectious diseases that is relevant to vaccination is host-pathogen interactions as these may reveal the dynamics of bacterial antigen quantity and shed light into their putative role in infection (Figure 2). The availability of genomic sequences has led to development of assays, notably microarrays, targeted at the study of host-agent interactions at the gene and protein levels. First of all, suitable pathogen antigen targets must be present in sufficient quantities during infection in order to be recognized by the immune system. As described above, brucellae secrete factors in order to evade intracellular protective mechanisms and establish a niche in which they can replicate. Putatively, these antigens are secreted into the cytoplasm to alter normal function of host cells and manipulate intracellular trafficking (Figures 2, 3). As a result, these factors or those associated with them (i.e., secretion system) can potentially be processed and presented in MHC I molecules via the endogenous pathway (Figure 3), in alternate presentation pathways to $\mathrm{CD} 8^{+}$ $\mathrm{T}$ cells, a $\mathrm{T}$ cell subset important for protection against brucellosis (Oliveira and Splitter, 1995; Blanchard and Shastri, 2010; Grillo et al., 2012). Similar to Mycobacterium and Salmonella, protection studies in Brucella have demonstrated that immunization

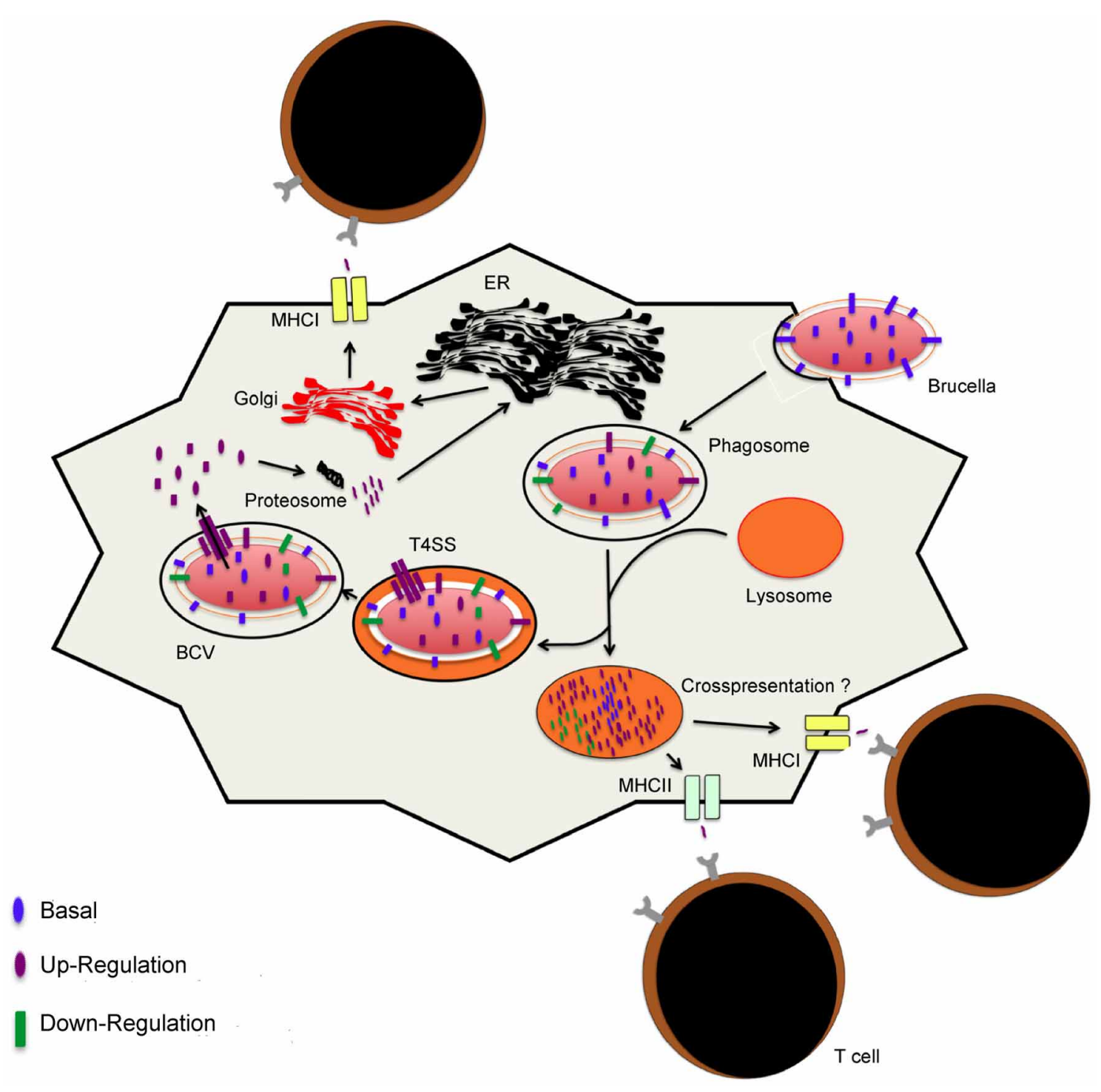

FIGURE 3 | Model for antigen presentation during Brucella infection. Upon internalization of Brucella, the conditions in the vacuole trigger changes in the gene expression profiles. Interactions or fusion with the lysosomes result in changes that support intracellular replication or lead to Brucella degradation, respectively. Peptides that result from degradation are presented via $\mathrm{MHCll}$ to helper T cells or, presumptively, to cytotoxic T cells via the vacuolar pathway of cross-presentation. Intracellular Brucella proteins are processed for presentation via $\mathrm{MHCl}$ molecules. Proteins are processed into peptides by host proteosomes in the cytosol. Peptides are loaded into $\mathrm{MHCl}$ molecules in the endoplasmic reticulum and packaged in the golgi apparatus for transportation to the surface of the host cell for presentation and activation of $T$ cells. 
with bacterial factors that are up-regulated during infection are of value in eliciting protective immunity (Rollenhagen et al., 2004; Lowry et al., 2011; Kao et al., 2012). Although work with Brucella spp. is limited, evidence for early success merits further investigation. Additionally, these antigens could potentially be virulence factors and serve as better antigens in a vaccine formulation based on the presumption that they are conserved and may be less prone to mutation due to their role in pathogenesis. For instance, LPS and the T4SS are important virulence factors with vital roles in intracellular survival that are present in the pathogenic strains B. melitensis, B. abortus, and B. suis (Carle et al., 2006; Wattam et al., 2009).

Overall, we propose that antigen selection for the development of subunit immunization regimen for Brucella spp. must include antigens that: (1) Contain antigenic determinants with protective relevance, a process that may be aided by in silico analysis of genomic sequences; (2) Are present at adequate levels during infection in an effort to provide a target for recognition and elimination of infected host cells by the primed immune system; and (3) Have a link to the pathogenesis of the agent with the intent to minimize the risk of mutation and resistance. We propose that consideration of host protective mechanisms and antigenic determinants, in vivo expression of pathogen molecular factors, and brucellae virulence-related factors in an antigen selection scheme will lead to the identification of immuno-protective Brucella spp. antigens (Figure 2).

\section{ENHANCING PROTECTIVE IMMUNE RESPONSES OF SUBUNIT VACCINES}

Two important considerations in subunit vaccination are adjuvant or delivery vehicle and route of immunization. Adjuvants are compounds co-administered with antigen that have the ability to affect the potency and quality of antigen-specific immune responses. In part due to their ability to stimulate innate immunity, adjuvants influence the ensuing adaptive immune response directed at the antigen (Coffman et al., 2010). Research efforts aimed at deciphering the stimulatory effects of adjuvants have aided in their rational selection for inclusion in subunit vaccine formulations when the general protective immuno-mechanisms against the pathogen of interest are known. Adjuvants almost invariably stimulate humoral immunity but can be selected based on their ability to stimulate a combination of Th1, Th2, Th17, and $\mathrm{CD}^{+}{ }^{+}$T-cell responses (Coffman et al., 2010). From these, targeting activation and proliferation of $\mathrm{CD} 8^{+} \mathrm{T}$ cells and stimulation of a Th1 response are important when considering vaccine development for brucellae. While Poly-IC, imiquimods, CpG, ISCOMS (immuno-stimulatory complexes) have been demonstrated to result in Th1 and $\mathrm{CD}^{+} \mathrm{T}$ cells, CAF10 and MPL stimulate Th1 skewed responses (Coffman et al., 2010; Duewell et al., 2011). Despite the role that Th1 and CD8 ${ }^{+} \mathrm{T}$ cell responses play in protection against brucellosis, the majority of Brucella spp. subunit immunization studies have and continue to primarily use Alum (aluminum salts) or Freund's adjuvant (FA) in immunization formulations (Pasquevich et al., 2009, 2011; Lowry et al., 2011; Yang et al., 2011a,b; Fu et al., 2012; Goel and Bhatnagar, 2012; Jain et al., 2012; Li et al., 2012). This practice is inconsistent with the protective mechanisms against brucellosis since Alum is primarily associated with a Th2 response, FA elicits a mixed Th1/Th2 response and both have no demonstrated ability to stimulate of $\mathrm{CD}^{+} \mathrm{T}$ cell responses (Coffman et al., 2010); however, the use of Alum may be associated with its acceptance for use in human subjects.

The field of adjuvant/antigen subunit vaccine formulation is an area that merits further exploration in the context of Brucella spp. vaccinology. An immunization study revealed that protection against virulent brucellae challenge was dependent on adjuvant where co-administration with CpG ODN, a TLR agonist, but not non-CpG ODN or protein (P39) alone resulted in protection against challenge (Al-Mariri et al., 2001). Another study demonstrated that mice inoculated with L7/L12 in liposomes had a greater ability to clear Brucella spp. than mice immunized with antigen and FA (Mallick et al., 2007). Nonetheless, another study reported no difference in protection regardless of whether MPL, FA, or Alum was used (Velikovsky et al., 2003).

The use of recombinant vectors is another viable option for delivering subunit antigens. Viral and bacterial vectors that are safe for use in vaccine formulations have been developed and are currently used for immunization with subunit antigens. One of the appealing characteristics of this type of vaccination platform is their ability to induce cell-mediated immunity, particularly cytotoxic T lymphocytes (Harms et al., 2009; Rollier et al., 2011). Given the role of these cells in protection against intracellular pathogens, this is an appealing approach in brucellosis subunit vaccinology. The use of $E$. coli as the delivery vehicle for recombinant Brucella spp. antigens (i.e., P39) demonstrated that this platform induced only marginal levels of protection (Al-Mariri, 2010; Al-Mariri et al., 2012). However, the combination of the recombinant bacterial vector with a TLR agonist enhanced the protective effect of the formulation to a level that approached that elicited by a live-attenuated vaccine strain (Al-Mariri et al., 2012). A point of consideration is that these studies used the non-invasive E. coli strain BL-21, which perhaps affected downstream antigen processing as a result of the mode of antigen uptake (i.e., active vs. passive) by antigen presenting cells. The elaboration and use of a recombinant invasive E. coli strain to deliver antigens revealed promising results in mouse studies (Harms et al., 2009; Gupta et al., 2012). Lastly, the use of Lactococcus and Ochrobactrum over-expressing Brucella spp. antigens has also been evaluated and shown to confer partial protection against challenge (Saez et al., 2012). However, the fact that these two bacterial strains are avirulent may again have an effect on antigen presentation as they may be highly attenuated intracellularly and potentially result in limited antigen production or be internalized by APCs through routes that do not fully stimulate desired immunity. Other promising bacterial vectors such as Salmonella, an intracellular pathogen, are also available but have not been evaluated in the context of brucellosis (Galen et al., 2009). The advantages of using the Salmonella live vaccine are that this bacterium is a potent stimulator of innate immunity, targets internalization by antigen presenting cells and has an intracellular lifestyle with a well-defined capacity for protein production and secretion in the intracellular compartment. The use of recombinant viral vectors is another area that may prove useful in delivery of subunit antigens. Despite its widespread use 
in the literature, its use in brucellosis is limited (Perkins et al., 2010).

Another area that merits consideration in Brucella subunit vaccinology is the route of immunization. Immunization with Brucella LPS complexed with Neisseria OMP resulted in better protection to intranasal challenge following parenteral compared to intranasal immunization (Bhattacharjee et al., 2006). However, potential antigen degradation via the mucosal route was not accounted for in this study. Similarly, lipoproteins co-delivered with cholera toxin conferred protection against Brucella challenge in animals immunized via the mucosal route but the degree of protection was not as high as that obtained in mice immunized via the parenteral route (Pasquevich et al., 2011). The identification of measures to enhance mucosal protective immunity is an area of interest in brucellosis vaccinology as the main route of brucellae infection is through mucosal surfaces.

Entrapment of antigen in particles for delivery is yet another option for subunit immunization. In the context of Brucella subunit vaccinology little is known about particulate antigen delivery. Several physical aspects of particles have been linked to their effect on the immune system and include particle size, chemical composition, erosion rate, surface chemistry, and immunization route as thoroughly reviewed elsewhere (Oyewumi et al., 2010; Rice-Ficht et al., 2010). Other than affecting size-dependent penetration of anatomical barriers, there is evidence that supports particle size playing a role on the quality of the ensuing immunity relative to humoral and/or cell-mediated responses following immunization (Oyewumi et al., 2010). Additionally, the use of particles may aid in preventing antigen degradation when mucosa is the intended route of immunization, enhance uptake by dendritic cells, and macrophages, and act as a focus for prolonged antigen release acting as a self-boosting mechanism (Oyewumi et al., 2010). In brucellosis research, delivery of antigen in the form of outer membrane vesicles, in liposomes, or in polymeric particles has been explored to a limited extent (Estevan et al., 2006; Munoz et al., 2006; Mallick et al., 2007; Jain-Gupta et al., 2012). Therefore, antigen delivery in polymeric particles is an area with encouraging potential in subunit antigen immunization against brucellosis. Given that the physical properties of particles can have an effect on the resulting immune response, these can potentially be designed to deliver antigen and stimulate antigen-specific protective immunity against brucellosis.

\section{REFERENCES}

Adams, L. G. (2002). The pathology of brucellosis reflects the outcome of the battle between the host genome and the Brucella genome. Vet. Microbiol. 90, 553-561.

Alix, E., Mukherjee, S., and Roy, C. R. (2011). Subversion of membrane transport pathways by vacuolar pathogens. J. Cell Biol. 195, 943-952.

Al-Mariri, A. (2010). Protection of $\mathrm{BALB} / \mathrm{c}$ mice against Brucella melitensis $16 \mathrm{M}$ infection induced by vaccination with live Escherchia

\section{CONCLUSIONS}

The antigen, delivery vehicle or adjuvant, and delivery route are key components that merit careful consideration in the development of a subunit vaccine against brucellosis (de Veer and Meeusen, 2011; Levitz and Golenbock, 2012). However, the identification of suitable antigens may represent the most challenging aspect. Significant advances in the fields of immunology, microbiology, and bioinformatics and their application to the understanding of host-agent interactions have provided insight for the strategic design of better-targeted tools that aim to identify protective antigens.

There are important criteria that must be met in an effort to maximize the probability of arriving at the identification of a suitable antigen. First, the candidate immunogen must have antigenic determinants. As discussed above, a T-cell mediated response is generally critical for protection against brucellosis. Therefore, the inclusion of antigens with MHC I and MHC II epitopes for the priming of $\mathrm{CD}^{+}$and $\mathrm{CD}^{+} \mathrm{T}$ cells, respectively, should be included in the screening of candidate antigens. Accordingly, an antigen delivery vehicle that targets both the endogenous and exogenous antigen presentation pathways needs to be considered. In order to target protective humoral immunity, a deeper understanding of the precise mechanisms and associated antibody isotypes, quantities and temporal dynamics involved in the protection against Brucella spp. is needed. Secondly, the level of antigen present during infection must be considered for two main reasons. One, high antigen levels during infection may indicate that those antigens are necessary for adaptation or replication of the pathogen. Two, availability of suitable quantities of antigen to serve as a source for antigen processing and presentation may enhance elimination of infected cells as a result of recognition by the immune system. Thirdly, the adjuvant or delivery platform selection is a critical component of vaccine formulation. The delivery system must support the development of a Th1 and $\mathrm{CD}^{+} \mathrm{T}$ cell immune responses, consistent with the immuno-mechanisms that confer host protection against brucellae. Finally, appropriate combination of adjuvants and/or delivery systems may be required to potentiate desired immune responses that aid in enhancing protective efficacy. We propose that all these parameters merit consideration in the discovery of Brucella spp. subunit antigens and vaccine development.

proteins with $\mathrm{CpG}$ oligodeoxynucleotides as adjuvant. Infect. Immun. 69, 4816-4822.

Araya, L. N., Elzer, P. H., Rowe, G. E., Enright, F. M., and Winter, A. J. (1989). Temporal development of protective cellmediated and humoral immunity in $\mathrm{BALB} / \mathrm{c}$ mice infected with Brucella abortus. J. Immunol. 143 , 3330-3337.

Ashford, D. A., di Pietra, J., Lingappa, J., Woods, C., Noll, H., Neville, B., et al. (2004). Adverse events in humans associated with accidental exposure to the livestock brucellosis vaccine RB51. Vaccine 22, 3435-3439.

Atluri, V. L., Xavier, M. N., de Jong, M. F., den Hartigh, A. B., and Tsolis, R. E. (2011). Interactions of the human pathogenic Brucella species with their hosts. Annu. Rev. Microbiol. 65, 523-541.

Bagnoli, F., Baudner, B., Mishra, R. P., Bartolini, E., Fiaschi, L., Mariotti, P., et al. (2011). Designing the next generation of vaccines for global public health. OMICS 15, 545-566.

Baldwin, C. L., and Parent, M. (2002). Fundamentals of host immune response against Brucella abortus: 
what the mouse model has revealed about control of infection. Vet. Microbiol. 90, 367-382.

Barquero-Calvo, E., Conde-Alvarez, R., Chacon-Diaz, C., Quesada-Lobo, L., Martirosyan, A., Guzman-Verri, C., et al. (2009). The differential interaction of Brucella and Ochrobactrum with innate immunity reveals traits related to the evolution of stealthy pathogens. PLoS ONE 4:e5893. doi: 10.1371/journal. pone.0005893

Barrionuevo, P., Cassataro, J., Delpino, M. V., Zwerdling, A., Pasquevich, K. A., Garcia Samartino, C., et al. (2008). Brucella abortus inhibits major histocompatibility complex class II expression and antigen processing through interleukin-6 secretion via Toll-like receptor 2. Infect. Immun. 76, 250-262.

Bessoles, S., Ni, M., Garcia-Jimenez, S., Sanchez, F., and Lafont, V. (2011). Role of NKG2D and its ligands in the anti-infectious activity of Vgamma9Vdelta2 $\mathrm{T}$ cells against intracellular bacteria. Eur. J. Immunol. 41, 1619-1628.

Bhattacharjee, A. K., Izadjoo, M. J., Zollinger, W. D., Nikolich, M. P., and Hoover, D. L. (2006). Comparison of protective efficacy of subcutaneous versus intranasal immunization of mice with a Brucella melitensis lipopolysaccharide subunit vaccine. Infect. Immun. 74, 5820-5825.

Billard, E., Cazevieille, C., Dornand, J., and Gross, A. (2005). High susceptibility of human dendritic cells to invasion by the intracellular pathogens Brucella suis, B. abortus, and B. melitensis. Infect. Immun. 73, 8418-8424.

Billard, E., Dornand, J., and Gross, A. (2007). Brucella suis prevents human dendritic cell maturation and antigen presentation through regulation of tumor necrosis factor alpha secretion. Infect. Immun. 75, 4980-4989.

Blanchard, N., and Shastri, N. (2010). Cross-presentation of peptides from intracellular pathogens by $\mathrm{MHC}$ class I molecules. Ann. N.Y. Acad. Sci. 1183, 237-250.

Blasco, J. M., and Diaz, R. (1993). Brucella melitensis Rev-1 vaccine as a cause of human brucellosis. Lancet 342, 805.

Bos, M. P., Robert, V., and Tommassen, J. (2007). Biogenesis of the gramnegative bacterial outer membrane. Annu. Rev. Microbiol. 61, 191-214.

Boschiroli, M. L., Ouahrani-Bettache, S., Foulongne, V., MichauxCharachon, S., Bourg, G., Allardet-Servent, A., et al. (2002).
The Brucella suis virB operon is induced intracellularly in macrophages. Proc. Natl. Acad. Sci. U.S.A. 99, 1544-1549.

Bosio, C. M., and Dow, S. W. (2005). Francisella tularensis induces aberrant activation of pulmonary dendritic cells. J. Immunol. 175, 6792-6801.

Bossi, P., Tegnell, A., Baka, A., Van Loock, F., Hendriks, J., Werner, A., et al. (2004). Bichat guidelines for the clinical management of brucellosis and bioterrorism-related brucellosis. Euro Surveill. 9, E15-E16.

Brandao, A. P., Oliveira, F. S., Carvalho, N. B., Vieira, L. Q., Azevedo, V., Macedo, G. C., et al. (2012). Host susceptibility to Brucella abortus infection is more pronounced in IFN-gamma knockout than IL-12/beta2-microglobulin doubledeficient mice. Clin. Dev. Immunol. 2012:589494. doi: 10.1155/2012/ 589494

Briones, G., Inon de Iannino, N., Roset, M., Vigliocco, A., Paulo, P. S., and Ugalde, R. A. (2001). Brucella abortus cyclic beta-1, 2-glucan mutants have reduced virulence in mice and are defective in intracellular replication in HeLa cells. Infect. Immun. 69, 4528-4535.

Campbell, G. A., Adams, L. G., and Sowa, B. A. (1994). Mechanisms of binding of Brucella abortus to mononuclear phagocytes from cows naturally resistant or susceptible to brucellosis. Vet. Immunol. Immunopathol. 41, 295-306.

Carle, A., Hoppner, C., Ahmed Aly, K., Yuan, Q., den Dulk-Ras, A., Vergunst, A., et al. (2006). The Brucella suis type IV secretion system assembles in the cell envelope of the heterologous host Agrobacterium tumefaciens and increases IncQ plasmid pLS1 recipient competence. Infect. Immun. 74, 108-117.

Casadevall, A., and Pirofski, L. A. (2006). A reappraisal of humoral immunity based on mechanisms of antibody-mediated protection against intracellular pathogens. $A d v$. Immunol. 91, 1-44.

Cassataro, J., Estein, S. M., Pasquevich, K. A., Velikovsky, C. A., de la Barrera, S., Bowden, R., et al. (2005). Vaccination with the recombinant Brucella outer membrane protein 31 or a derived 27 -aminoacid synthetic peptide elicits a CD4+ $\mathrm{T}$ helper 1 response that protects against Brucella melitensis infection. Infect. Immun. 73, 8079-8088.

Cassataro, J., Velikovsky, C. A., Bruno, L., Estein, S. M., de la Barrera, S., Bowden, R., et al. (2007). Improved immunogenicity of a vaccination regimen combining a DNA vaccine encoding Brucella melitensis outer membrane protein 31 (Omp31) and recombinant Omp31 boosting. Clin. Vaccine Immunol. 14, 869-874.

Castaneda-Roldan, E. I., OuahraniBettache, S., Saldana, Z., Avelino, F., Rendon, M. A., Dornand, J., et al. (2006). Characterization of SP41, a surface protein of Brucella associated with adherence and invasion of host epithelial cells. Cell Microbiol. 8, 1877-1887.

Celli, J., de Chastellier, C., Franchini, D. M., Pizarro-Cerda, J., Moreno, E., and Gorvel, J. P. (2003). Brucella evades macrophage killing via VirBdependent sustained interactions with the endoplasmic reticulum. J. Exp. Med. 198, 545-556.

Celli, J., Salcedo, S. P., and Gorvel, J. P. (2005). Brucella coopts the small GTPase Sar1 for intracellular replication. Proc. Natl. Acad. Sci. U.S.A. 102, 1673-1678.

Chaudhary, A., Ganguly, K., Cabantous, S., Waldo, G. S., Micheva-Viteva, S. N., Nag, K., et al. (2012). The Brucella TIRlike protein $\mathrm{TcpB}$ interacts with the death domain of MyD88. Biochem. Biophys. Res. Commun. 417, 299-304.

Chen, C., Dow, C., Wang, P., Sidney, J., Read, A., Harmsen, A., et al. (2011). Identification of CD4+ T cell epitopes in C. burnetii antigens targeted by antibody responses. PLoS ONE 6:e17712. doi: 10.1371/ journal.pone.0017712

Chen, D. J., Osterrieder, N., Metzger, S. M., Buckles, E., Doody, A. M., DeLisa, M. P., et al. (2010). Delivery of foreign antigens by engineered outer membrane vesicle vaccines. Proc. Natl. Acad. Sci. U.S.A. 107, 3099-3104.

Chomel, B. B., DeBess, E. E., Mangiamele, D. M., Reilly, K. F., Farver, T. B., Sun, R. K., et al. (1994). Changing trends in the epidemiology of human brucellosis in California from 1973 to 1992: a shift toward foodborne transmission. J. Infect. Dis. 170, 1216-1223.

Cloeckaert, A., Vizcaino, N., Paquet, J. Y., Bowden, R. A., and Elzer, P. H. (2002). Major outer membrane proteins of Brucella spp.: past, present and future. Vet. Microbiol. 90, 229-247.

Coffman, R. L., Sher, A., and Seder, R. A. (2010). Vaccine adjuvants: putting innate immunity to work. Immunity 33, 492-503.

Corbel, M. J. (1976). The immunogenic activity of ribosomal fractions derived from Brucella abortus. J. Hyg. (Lond.) 76, 65-74.

Corbel, M. J., World Health Organization, Food and Agriculture Organization of the United Nations, International Office of Epizootics, and ebrary Inc. (2006). Brucellosis in Humans and Animals. Geneva: World Health Organization.

Cossart, P., and Roy, C. R. (2010). Manipulation of host membrane machinery by bacterial pathogens. Curr. Opin. Cell Biol. 22, 547-554.

Czibener, C., and Ugalde, J. E. (2012). Identification of a unique gene cluster of Brucella spp. that mediates adhesion to host cells. Microbes Infect. 14, 79-85.

David, R. (2012). Cellular microbiology: an unconventional exit for Brucella. Nat. Rev. Microbiol. 10, 160.

de Jong, M. F., Sun, Y. H., den Hartigh, A. B., van Dijl, J. M., and Tsolis, R. M. (2008). Identification of VceA and VceC, two members of the VjbR regulon that are translocated into macrophages by the Brucella type IV secretion system. Mol. Microbiol. 70, 1378-1396.

den Hartigh, A. B., Rolan, H. G., de Jong, M. F., and Tsolis, R. M. V. (2008). VirB3 to VirB6 and VirB8 to VirB11, but not VirB7, are essential for mediating persistence of Brucella in the reticuloendothelial system. J. Bacteriol. 190, 4427-4436. de Veer, M., and Meeusen, E. (2011). New developments in vaccine research-unveiling the secret of vaccine adjuvants. Discov. Med. 12, 195-204.

Duewell, P., Kisser, U., Heckelsmiller, K., Hoves, S., Stoitzner, P., Koernig, S., et al. (2011). ISCOMATRIX adjuvant combines immune activation with antigen delivery to dendritic cells in vivo leading to effective cross-priming of CD8+ T cells. J. Immunol. 187, 55-63.

Durward, M., Radhakrishnan, G., Harms, J., Bareiss, C., Magnani, D., and Splitter, G. A. (2012). Active evasion of CTL mediated killing and low quality responding CD8+ $\mathrm{T}$ cells contribute to persistence of Brucellosis. PLoS ONE 7:e34925. doi: 10.1371/journal.pone.0034925

Eckman, M. R. (1975). Brucellosis linked to Mexican cheese. JAMA 232, 636-637.

Elzer, P. H., Jacobson, R. H., Jones, S. M., Nielsen, K. H., Douglas, J. T., and Winter, A. J. (1994). Antibody-mediated protection against Brucella abortus in BALB/c mice at successive periods after infection: variation between virulent strain 2308 and attenuated 
vaccine strain 19. Immunology 82, 651-658.

Eriksson, S., Lucchini, S., Thompson, A., Rhen, M., and Hinton, J. C. (2003). Unravelling the biology of macrophage infection by gene expression profiling of intracellular Salmonella enterica. Mol. Microbiol. 47, 103-118.

Estevan, M., Gamazo, C., Grillo, M. J., Del Barrio, G. G., Blasco, J. M., and Irache, J. M. (2006). Experiments on a sub-unit vaccine encapsulated in microparticles and its efficacy against Brucella melitensis in mice. Vaccine 24, 4179-4187.

Falagas, M. E., and Bliziotis, I. A. (2006). Quinolones for treatment of human brucellosis: critical review of the evidence from microbiological and clinical studies. Antimicrob. Agents Chemother. 50, 22-33.

Fernandes, D. M., Benson, R., and Baldwin, C. L. (1995). Lack of a role for natural killer cells in early control of Brucella abortus 2308 infections in mice. Infect. Immun. 63, 4029-4033.

Ficht, T. A., Kahl-McDonagh, M. M., Arenas-Gamboa, A. M., and RiceFicht, A. C. (2009). Brucellosis: the case for live, attenuated vaccines. Vaccine 27(Suppl. 4), D40-D43.

Finco, O., Frigimelica, E., Buricchi, F., Petracca, R., Galli, G., Faenzi, E., et al. (2011). Approach to discover $\mathrm{T}$ - and B-cell antigens of intracellular pathogens applied to the design of Chlamydia trachomatis vaccines. Proc. Natl. Acad. Sci. U.S.A. 108, 9969-9974.

Fontan, P., Aris, V., Ghanny, S., Soteropoulos, P., and Smith, I. (2008). Global transcriptional profile of Mycobacterium tuberculosis during THP-1 human macrophage infection. Infect. Immun. 76, 717-725.

Franco, M. P., Mulder, M., Gilman, R. H., and Smits, H. L. (2007). Human brucellosis. Lancet Infect. Dis. 7, 775-786.

Frey, J. (2007). Biological safety concepts of genetically modified live bacterial vaccines. Vaccine 25, 5598-5605.

Fu, S., Xu, J., Li, X., Xie, Y., Qiu, Y., Du, X., et al. (2012). Immunization of mice with recombinant protein CobB or AsnC confers protection against Brucella abortus infection. PLoS ONE 7:e29552. doi: 10.1371/ journal.pone.0029552

Fugier, E., Salcedo, S. P., de Chastellier, C., Pophillat, M., Muller, A., Arce-Gorvel, V., et al. (2009). The glyceraldehyde-3-phosphate dehydrogenase and the small GTPase
Rab 2 are crucial for Brucella replication. PLoS Pathog. 5:e1000487. doi: 10.1371/journal.ppat.1000487

Fukuto, H. S., Svetlanov, A., Palmer, L. E., Karzai, A. W., and Bliska, J. B. (2010). Global gene expression profiling of Yersinia pestis replicating inside macrophages reveals the roles of a putative stress-induced operon in regulating type III secretion and intracellular cell division. Infect. Immun. 78, 3700-3715.

Galen, J. E., Pasetti, M. F., Tennant, S., Ruiz-Olvera, P., Sztein, M. B., and Levine, M. M. (2009). Salmonella enterica serovar Typhi live vector vaccines finally come of age. Immunol. Cell. Biol. 87, 400-412.

Gao, N., Jennings, P., Guo, Y., and Yuan, D. (2011). Regulatory role of natural killer (NK) cells on antibody responses to Brucella abortus. Innate Immun. 17, 152-163.

Garcia Samartino, C., Delpino, M. V., Pott Godoy, C., Di Genaro, M. S., Pasquevich, K. A., Zwerdling, A., et al. (2010). Brucella abortus induces the secretion of proinflammatory mediators from glial cells leading to astrocyte apoptosis. Am. J. Pathol. 176, 1323-1338.

Giambartolomei, G. H., Delpino, M. V., Cahanovich, M. E., Wallach, J. C., Baldi, P. C., Velikovsky, C. A., et al. (2002). Diminished production of $\mathrm{T}$ helper 1 cytokines correlates with $\mathrm{T}$ cell unresponsiveness to Brucella cytoplasmic proteins in chronic human brucellosis. J. Infect. Dis. 186, 252-259.

Glynn, M. K., and Lynn, T. V. (2008). Brucellosis. J. Am. Vet. Med. Assoc. 233, 900-908.

Godfroid, J., Cloeckaert, A., Liautard, J. P., Kohler, S., Fretin, D., Walravens, K., et al. (2005). From the discovery of the Malta fever's agent to the discovery of a marine mammal reservoir, brucellosis has continuously been a re-emerging zoonosis. Vet. Res. 36, 313-326.

Goel, D., and Bhatnagar, R. (2012). Intradermal immunization with outer membrane protein 25 protects $\mathrm{Balb} / \mathrm{c}$ mice from virulent $B$. abortus 544. Mol. Immunol. 51, 159-168.

Goenka, R., Parent, M. A., Elzer, P. H., and Baldwin, C. L. (2011). B cell-deficient mice display markedly enhanced resistance to the intracellular bacterium Brucella abortus. J. Infect. Dis. 203, 1136-1146.

Golding, B., Scott, D. E., Scharf, O., Huang, L. Y., Zaitseva, M., Lapham, C., et al. (2001). Immunity and protection against Brucella abortus. Microbes Infect. 3, 43-48.
Gorvel, J. P., and Moreno, E. (2002). Brucella intracellular life: from invasion to intracellular replication. Vet. Microbiol. 90, 281-297.

Grillo, M. J., Blasco, J. M., Gorvel, J. P., Moriyon, I., and Moreno, E. (2012). What have we learned from brucellosis in the mouse model? Vet. Res. 43, 29.

Gross, A., Terraza, A., OuahraniBettache, S., Liautard, J. P., and Dornand, J. (2000). In vitro Brucella suis infection prevents the programmed cell death of human monocytic cells. Infect. Immun. 68 342-351.

Gupta, V. K., Radhakrishnan, G., Harms, J., and Splitter, G. (2012). Invasive Escherichia coli vaccines expressing Brucella melitensis outer membrane proteins 31 or 16 or periplasmic protein BP26 confer protection in mice challenged with B. melitensis. Vaccine 30, 4017-4022.

Guzman-Verri, C., Manterola, L., SolaLanda, A., Parra, A., Cloeckaert, A., Garin, J., et al. (2002). The two-component system BvrR/BvrS essential for Brucella abortus virulence regulates the expression of outer membrane proteins with counterparts in members of the Rhizobiaceae. Proc. Natl. Acad. Sci. U.S.A. 99, 12375-12380.

Haag, A. F., Myka, K. K., Arnold, M. F., Caro-Hernandez, P., and Ferguson, G. P. (2010). Importance of Lipopolysaccharide and Cyclic beta-1, 2-Glucans in BrucellaMammalian Infections. Int. J. Microbiol. 2010:124509. doi: 10.1155/2010/124509

Harms, J. S., Durward, M. A., Magnani, D. M., and Splitter, G. A. (2009). Evaluation of recombinant invasive, non-pathogenic Eschericia coli as a vaccine vector against the intracellular pathogen, Brucella. J. Immune Based Ther. Vaccines. 7:1. doi: 10.1186/1476-8518-7-1

He, Y., Reichow, S., Ramamoorthy, S., Ding, X., Lathigra, R., Craig, J. C., et al. (2006). Brucella melitensis triggers time-dependent modulation of apoptosis and down-regulation of mitochondrion-associated gene expression in mouse macrophages. Infect. Immun. 74, 5035-5046.

He, Y., Xiang, Z., and Mobley, H. L. (2010). Vaxign: the first web-based vaccine design program for reverse vaccinology and applications for vaccine development. J. Biomed. Biotechnol. 2010:297505. doi: 10.1155/2010/297505

Hernandez-Castro, R., VerdugoRodriguez, A., Puente, J. L., and Suarez-Guemes, F. (2008). The BMEI0216 gene of Brucella melitensis is required for internalization in HeLa cells. Microb. Pathog. 44, 28-33.

Hoffmann, E. M., and Houle, J. J. (1995). Contradictory roles for antibody and complement in the interaction of Brucella abortus with its host. Crit. Rev. Microbiol. 21, 153-163.

Hong, P. C., Tsolis, R. M., and Ficht, T. A. (2000). Identification of genes required for chronic persistence of Brucella abortus in mice. Infect. Immun. 68, 4102-4107.

Hybiske, K., and Stephens, R. S. (2008). Exit strategies of intracellular pathogens. Nat. Rev. Microbiol. 6, 99-110.

Iwasaki, A. (2007). Mucosal dendritic cells. Annu. Rev. Immunol. 25, 381-418.

Jain, S., Afley, P., and Kumar, S. (2012). Immunological responses to recombinant cysteine synthase A of Brucella abortus in BALB/c mice. World J. Microbiol. Biotechnol. 29, 907-913.

Jain-Gupta, N., Contreras-Rodriguez, A., Vemulapalli, R., Witonsky, S. G., Boyle, S. M., and Sriranganathan, N. (2012). Pluronic P85 enhances the efficacy of outer membrane vesicles as a subunit vaccine against Brucella melitensis challenge in mice. FEMS Immunol. Med. Microbiol. 66, 436-444.

Jimenez de Bagues, M. P., Terraza, A., Gross, A., and Dornand, J. (2004). Different responses of macrophages to smooth and rough Brucella spp.: relationship to virulence. Infect. Immun. 72, 2429-2433.

Jubier-Maurin, V., Boigegrain, R. A., Cloeckaert, A., Gross, A., AlvarezMartinez, M. T., Terraza, A., et al. (2001). Major outer membrane protein Omp25 of Brucella suis is involved in inhibition of tumor necrosis factor alpha production during infection of human macrophages. Infect. Immun. 69, 4823-4830.

Kamath, A. T., Rochat, A. F., Christensen, D., Agger, E. M., Andersen, P., Lambert, P. H., et al. (2009). A liposome-based mycobacterial vaccine induces potent adult and neonatal multifunctional $\mathrm{T}$ cells through the exquisite targeting of dendritic cells. PLoS ONE 4:e5771. doi: 10.1371/journal.pone.0005771

Kao, F. F., Mahmuda, S., Pinto, R., Triccas, J. A., West, N. P., and Britton, W. J. (2012). The secreted lipoprotein, MPT83, of Mycobacterium tuberculosis is recognized during human tuberculosis and stimulates protective immunity 
in mice. PLoS ONE 7:e34991. doi: 10.1371/journal.pone.0034991

Karunakaran, K. P., Yu, H., Foster, L. J., and Brunham, R. C. (2010). Development of a Chlamydia trachomatis $\mathrm{T}$ cell Vaccine. Hum. Vaccin. 6, 676-680.

Ko, J., and Splitter, G. A. (2003). Molecular host-pathogen interaction in brucellosis: current understanding and future approaches to vaccine development for mice and humans. Clin. Microbiol. Rev. 16, 65-78.

Laloux, G., Deghelt, M., de Barsy, M., Letesson, J. J., and De Bolle, X. (2010). Identification of the essential Brucella melitensis porin Omp2b as a suppressor of Bax-induced cell death in yeast in a genome-wide screening. PLoS ONE 5:e13274. doi: 10.1371/journal.pone.0013274

Lamontagne, J., Butler, H., ChavesOlarte, E., Hunter, J., Schirm, M., Paquet, C., et al. (2007). Extensive cell envelope modulation is associated with virulence in Brucella abortus. J. Proteome Res. 6, 1519-1529.

Lapaque, N., Forquet, F., de Chastellier, C., Mishal, Z., Jolly, G., Moreno, E., et al. (2006). Characterization of Brucella abortus lipopolysaccharide macrodomains as mega rafts. Cell. Microbiol. 8, 197-206.

Lapaque, N., Moriyon, I., Moreno, E., and Gorvel, J. P. (2005). Brucella lipopolysaccharide acts as a virulence factor. Curr. Opin. Microbiol. $8,60-66$.

Levitz, S. M., and Golenbock, D. T. (2012). Beyond empiricism: informing vaccine development through innate immunity research. Cell 148, 1284-1292.

Li, X., Xu, J., Xie, Y., Qiu, Y., Fu, S., Yuan, X., et al. (2012). Vaccination with recombinant flagellar proteins FlgJ and FliN induce protection against Brucella abortus 544 infection in BALB/c mice. Vet. Microbiol. $161,137-144$

Liang, L., Leng, D., Burk, C., NakajimaSasaki, R., Kayala, M. A., and Atluri, V. L., et al. (2010). Large scale immune profiling of infected humans and goats reveals differential recognition of Brucella melitensis antigens. PLoS Negl. Trop. Dis. 4:e673. doi: 10.1371/journal.pntd. 0000673

Liebenberg, J., Pretorius, A., Faber, F. E., Collins, N. E., Allsopp, B. A., and van Kleef, M. (2012). Identification of Ehrlichia ruminantium proteins that activate cellular immune responses using a reverse vaccinology strategy. Vet. Immunol. Immunopathol. 145, 340-349.
Lowry, J. E., Isaak, D. D., Leonhardt, J. A., Vernati, G., Pate, J. C., and Andrews, G. P. (2011). Vaccination with Brucella abortus recombinant in vivo-induced antigens reduces bacterial load and promotes clearance in a mouse model for infection. PLoS ONE 6:e17425. doi: 10.1371/ journal.pone. 0017425

Lucchini, S., Liu, H., Jin, Q., Hinton, J. C., and Yu, J. (2005). Transcriptional adaptation of Shigella flexneri during infection of macrophages and epithelial cells: insights into the strategies of a cytosolic bacterial pathogen. Infect. Immun. 73, 88-102.

Lucero, N. E., Ayala, S. M., Escobar, G. I., and Jacob, N. R. (2008). Brucella isolated in humans and animals in Latin America from 1968 to 2006. Epidemiol. Infect. 136, 496-503.

Mallick, A. I., Singha, H., Chaudhuri, P., Nadeem, A., Khan, S. A., Dar, K. A., et al. (2007). Liposomised recombinant ribosomal L7/L12 protein protects $\mathrm{BALB} / \mathrm{c}$ mice against Brucella abortus 544 infection. Vaccine 25, 3692-3704.

Manterola, L., Guzman-Verri, C., Chaves-Olarte, E., Barquero-Calvo, E., de Miguel, M. J., Moriyon, I., et al. (2007). BvrR/BvrS-controlled outer membrane proteins Omp3a and Omp3b are not essential for Brucella abortus virulence. Infect. Immun. 75, 4867-4874.

Mantur, B. G., Amarnath, S. K., and Shinde, R. S. (2007). Review of clinical and laboratory features of human brucellosis. Indian J. Med. Microbiol. 25, 188-202.

Marchesini, M. I., Herrmann, C. K., Salcedo, S. P., Gorvel, J. P., and Comerci, D. J. (2011). In search of Brucella abortus type IV secretion substrates: screening and identification of four proteins translocated into host cells through VirB system. Cell Microbiol. 13, 1261-1274.

Martin, C. (2005). The dream of a vaccine against tuberculosis; new vaccines improving or replacing BCG? Eur. Respir. J. 26, 162-167.

Martin-Martin, A. I., Caro-Hernandez, P., Orduna, A., Vizcaino, N., and Fernandez-Lago, L. (2008). Importance of the Omp25/Omp31 family in the internalization and intracellular replication of virulent $B$. ovis in murine macrophages and HeLa cells. Microbes Infect. 10, 706-710.

Martin-Martin, A. I., Vizcaino, N., and Fernandez-Lago, L. (2010). Cholesterol, ganglioside GM1 and class A scavenger receptor contribute to infection by Brucella ovis and Brucella canis in murine macrophages. Microbes Infect. 12, 246-251.

McMurry, J. A., Kimball, S., Lee, J. H., Rivera, D., Martin, W., Weiner, D. B., et al. (2007). Epitopedriven TB vaccine development: a streamlined approach using immuno-informatics, ELISpot assays, and HLA transgenic mice. Curr. Mol. Med. 7, 351-368.

Moreno, E., and Moriyon, I. (2002). Brucella melitensis: a nasty bug with hidden credentials for virulence. Proc. Natl. Acad. Sci. U.S.A. 99, 1-3.

Moriyon, I., and Lopez-Goni, I. (1998). Structure and properties of the outer membranes of Brucella abortus and Brucella melitensis. Int. Microbiol. 1, 19-26.

Munoz, P. M., Estevan, M., Marin, C. M., Jesus De Miguel, M., Jesus Grillo, M., Barberan, M., et al. (2006). Brucella outer membrane complex-loaded microparticles as a vaccine against Brucella ovis in rams. Vaccine 24, 1897-1905.

Murphy, E., Robertson, G. T., Parent, M., Hagius, S. D., Roop, R. M. 2nd., Elzer, P. H., et al. (2002). Major histocompatibility complex class I and II expression on macrophages containing a virulent strain of Brucella abortus measured using green fluorescent protein-expressing brucellae and flow cytometry. FEMS Immunol. Med. Microbiol. 33, 191-200.

Murphy, E. A., Sathiyaseelan, J., Parent, M. A., Zou, B., and Baldwin, C. L. (2001). Interferon-gamma is crucial for surviving a Brucella abortus infection in both resistant C57BL/6 and susceptible BALB/C mice. Immunology 103, 511-518.

Nijskens, C., Copin, R., De Bolle, X., and Letesson, J. J. (2008). Intracellular rescuing of a $B$. melitensis $16 \mathrm{M}$ virB mutant by co-infection with a wild type strain. Microb. Pathog. 45, 134-141.

O'Callaghan, D., Cazevieille, C., Allardet-Servent, A., Boschiroli, M. L., Bourg, G., Foulongne, V., et al. (1999). A homologue of the Agrobacterium tumefaciens VirB and Bordetella pertussis Ptl type IV secretion systems is essential for intracellular survival of Brucella suis. Mol. Microbiol. 33, 1210-1220.

Oliveira, S. C., and Splitter, G. A. (1995). CD8+ type 1 CD44hi CD45 RBlo T lymphocytes control intracellular Brucella abortus infection as demonstrated in major histocompatibility complex class I- and class II-deficient mice. Eur. J. Immunol. 25, 2551-2557.

Oliveira, S. C., and Splitter, G. A. (1996). Immunization of mice with recombinant L7/L12 ribosomal protein confers protection against Brucella abortus infection. Vaccine 14, 959-962.

Oyewumi, M. O., Kumar, A., and Cui, Z. (2010). Nano-microparticles as immune adjuvants: correlating particle sizes and the resultant immune responses. Expert Rev. Vaccines 9, 1095-1107.

Pakzad, I., Rezaee, A., Rasaee, M. J., Tabbaraee, B., and Delpisheh, A. (2009). Immunogencity of HSAL7/L12 (Brucella abortus ribosomal protein) in an animal model. Iran J. Immunol. 6, 12-21.

Pappas, G., Akritidis, N., Bosilkovski, M., and Tsianos, E. (2005) Brucellosis. N. Engl. J. Med. 352, 2325-2336.

Pasquevich, K. A., Estein, S. M., Garcia Samartino, C., Zwerdling, A., Coria, L. M., Barrionuevo, P., et al. (2009). Immunization with recombinant Brucella species outer membrane protein Omp16 or Omp19 in adjuvant induces specific $\mathrm{CD} 4+$ and CD8+ $\mathrm{T}$ cells as well as systemic and oral protection against Brucella abortus infection. Infect. Immun. 77, 436-445.

Pasquevich, K. A., Ibanez, A. E., Coria, L. M., Garcia Samartino, C., Estein, S. M., Zwerdling, A., et al. (2011). An oral vaccine based on U-Omp19 induces protection against B.abortus mucosal challenge by inducing an adaptive IL-17 immune response in mice. PLoS ONE 6:e16203. doi: 10.1371/ journal.pone.0016203

Pei, J., Turse, J. E., and Ficht, T. A. (2008). Evidence of Brucella abortus OPS dictating uptake and restricting NF-kappaB activation in murine macrophages. Microbes Infect. 10, 582-590.

Perkins, S. D., Smither, S. J., and Atkins, H. S. (2010). Towards a Brucella vaccine for humans. FEMS Microbiol. Rev. 34, 379-394.

Pizarro-Cerda, J., Moreno, E., Sanguedolce, V., Mege, J. L., and Gorvel, J. P. (1998). Virulent Brucella abortus prevents lysosome fusion and is distributed within autophagosome-like compartments. Infect. Immun. 66, 2387-2392.

Plotkin, S. A. (2010). Correlates of protection induced by vaccination. Clin. Vaccine Immunol. 17, 1055-1065.

Porte, F., Naroeni, A., OuahraniBettache, S., and Liautard, J. P. (2003). Role of the Brucella suis lipopolysaccharide $\mathrm{O}$ antigen in phagosomal genesis and in inhibition of phagosome-lysosome fusion 
in murine macrophages. Infect. Immun. 71, 1481-1490.

Posadas, D. M., Ruiz-Ranwez, V., Bonomi, H. R., Martin, F. A., and Zorreguieta, A. (2012). BmaC, a novel autotransporter of Brucella suis, is involved in bacterial adhesion to host cells. Cell Microbiol. 14, 965-982.

Pruneau, L., Emboule, L., Gely, P., Marcelino, I., Mari, B., Pinarello, V., et al. (2012). Global gene expression profiling of Ehrlichia ruminantium at different stages of development. FEMS Immunol. Med. Microbiol. 64, 66-73.

Qin, Q. M., Pei, J., Ancona, V., Shaw, B. D., Ficht, T. A., and de Figueiredo, P. (2008). RNAi screen of endoplasmic reticulum-associated host factors reveals a role for IRElalpha in supporting Brucella replication. PLoS Pathog. 4:e1000110. doi: 10.1371/journal.ppat.1000110

Radhakrishnan, G. K., Harms, J. S., and Splitter, G. A. (2011). Modulation of microtubule dynamics by a TIR domain protein from the intracellular pathogen Brucella melitensis. Biochem. J. 439, 79-83.

Radhakrishnan, G. K., Yu, Q., Harms, J. S., and Splitter, G. A. (2009). Brucella TIR Domain-containing Protein Mimics Properties of the Toll-like Receptor Adaptor Protein TIRAP. J. Biol. Chem. 284, 9892-9898.

Rafiei, A., Ardestani, S. K., Kariminia, A., Keyhani, A., Mohraz, M., and Amirkhani, A. (2006). Dominant Th1 cytokine production in early onset of human brucellosis followed by switching towards Th2 along prolongation of disease. J. Infect. 53, 315-324.

Rappuoli, R. (2000). Reverse vaccinology. Curr. Opin. Microbiol. 3, 445-450.

Rice-Ficht, A. C., Arenas-Gamboa, A. M., Kahl-McDonagh, M. M., and Ficht, T. A. (2010). Polymeric particles in vaccine delivery. Curr. Opin. Microbiol. 13, 106-112.

Rockx-Brouwer, D., Chong, A., Wehrly, T. D., Child, R., Crane, D. D., Celli, J., et al. (2012). Low dose vaccination with attenuated Francisella tularensis strain SchuS4 mutants protects against tularemia independent of the route of vaccination. PLoS ONE 7:e37752. doi: 10.1371/ journal.pone.0037752

Rollenhagen, C., Sorensen, M., Rizos, K., Hurvitz, R., and Bumann, D. (2004). Antigen selection based on expression levels during infection facilitates vaccine development for an intracellular pathogen.
Proc. Natl. Acad. Sci. U.S.A. 101, 8739-8744.

Rollier, C. S., Reyes-Sandoval, A., Cottingham, M. G., Ewer, K., and Hill, A. V. (2011). Viral vectors as vaccine platforms: deployment in sight. Curr. Opin. Immunol. 23, 377-382.

Roset, M. S., Ciocchini, A. E., Ugalde, R. A., and Inon de Iannino, N. (2004). Molecular cloning and characterization of cgt, the Brucella abortus cyclic beta-1, 2-glucan transporter gene, and its role in virulence. Infect. Immun. 72, 2263-2271.

Rossetti, C. A., Galindo, C. L., Garner, H. R., and Adams, L. G. (2011). Transcriptional profile of the intracellular pathogen Brucella melitensis following $\mathrm{HeLa}$ cells infection. Microb. Pathog. 51, 338-344.

Saez, D., Fernandez, P., Rivera, A., Andrews, E., and Onate, A. (2012). Oral immunization of mice with recombinant Lactococcus lactis expressing $\mathrm{Cu}, \mathrm{Zn}$ superoxide dismutase of Brucella abortus triggers protective immunity. Vaccine 30 , 1283-1290.

Salcedo, S. P., Marchesini, M. I., Lelouard, H., Fugier, E., Jolly, G., Balor, S., et al. (2008). Brucella control of dendritic cell maturation is dependent on the TIR-containing protein Btp1. PLoS Pathog. 4:e21. doi: 10.1371/journal.ppat.0040021

Scholz, H. C., Nockler, K., Gollner, C., Bahn, P., Vergnaud, G., Tomaso, H., et al. (2010). Brucella inopinata sp. nov., isolated from a breast implant infection. Int. J. Syst. Evol. Microbiol. 60, 801-808.

Schurig, G. G., Sriranganathan, N., and Corbel, M. J. (2002). Brucellosis vaccines: past, present and future. Vet. Microbiol. 90, 479-496.

Seder, R. A., and Hill, A. V. (2000). Vaccines against intracellular infections requiring cellular immunity. Nature 406, 793-798.

Seleem, M. N., Boyle, S. M., and Sriranganathan, N. (2010). Brucellosis: a re-emerging zoonosis. Vet. Microbiol. 140, 392-398.

Sengupta, D., Koblansky, A., Gaines, J., Brown, T., West, A. P., Zhang, D., et al. (2010). Subversion of innate immune responses by Brucella through the targeted degradation of the TLR signaling adapter, MAL. J. Immunol. 184, 956-964.

Sette, A., and Rappuoli, R. (2010). Reverse vaccinology: developing vaccines in the era of genomics. Immunity 33, 530-541.

Shannon, J. G., and Heinzen, R. A. (2009). Adaptive immunity to the obligate intracellular pathogen
Coxiella burnetii. Immunol. Res. 43 , 138-148.

Skendros, P., Boura, P., Chrisagis, D., and Raptopoulou-Gigi, M. (2007). Diminished percentage of CD4+ T-lymphocytes expressing interleukine-2 receptor alpha in chronic brucellosis. J. Infect. 54 192-197.

Skendros, P., Pappas, G., and Boura, P. (2011). Cell-mediated immunity in human brucellosis. Microbes Infect. $13,134-142$.

Skyberg, J. A., Thornburg, T., Rollins, M., Huarte, E., Jutila, M. A., and Pascual, D. W. (2011). Murine and bovine gammadelta $\mathrm{T}$ cells enhance innate immunity against Brucella abortus infections. PLoS ONE 6:e21978. doi: 10.1371/journal. pone. 0021978

Sola-Landa, A., Pizarro-Cerda, J. Grillo, M. J., Moreno, E., Moriyon, I., Blasco, J. M., et al. (1998). A two-component regulatory system playing a critical role in plant pathogens and endosymbionts is present in Brucella abortus and controls cell invasion and virulence. Mol. Microbiol. 29, 125-138.

Spera, J. M., Ugalde, J. E., Mucci, J., Comerci, D. J., and Ugalde, R. A. (2006). A B lymphocyte mitogen is a Brucella abortus virulence factor required for persistent infection. Proc. Natl. Acad. Sci. U.S.A. 103, 16514-16519.

Starr, T., Child, R., Wehrly, T. D., Hansen, B., Hwang, S., Lopez-Otin, C., et al. (2012). Selective subversion of autophagy complexes facilitates completion of the Brucella intracellular cycle. Cell Host Microbe 11, 33-45.

Starr, T., Ng, T. W., Wehrly, T. D., Knodler, L. A., and Celli, J. (2008) Brucella intracellular replication requires trafficking through the late endosomal/lysosomal compartment. Traffic 9, 678-694.

Sundaramurthi, J. C., Brindha, S., Shobitha, S. R., Swathi, A., Ramanandan, P., and Hanna, L. E. (2012). In silico identification of potential antigenic proteins and promiscuous CTL epitopes in Mycobacterium tuberculosis. Infect. Genet. Evol. 12, 1312-1318.

Tabatabai, L. B., and Pugh, G. W Jr. (1994). Modulation of immune responses in $\mathrm{Balb} / \mathrm{c}$ mice vaccinated with Brucella abortus $\mathrm{Cu}-\mathrm{Zn}$ superoxide dismutase synthetic peptide vaccine. Vaccine 12, 919-924.

Taylor, J. P., and Perdue, J. N. (1989). The changing epidemiology of human brucellosis in Texas, 1977-1986. Am. J. Epidemiol. 130, 160-165.
Titball, R. W. (2008). Vaccines against intracellular bacterial pathogens. Drug Discov. Today 13, 596-600.

Turse, J. E., Pei, J., and Ficht, T. A. (2011). Lipopolysaccharidedeficient Brucella variants arise spontaneously during infection. Front. Microbiol. 2:54. doi: 10.3389/ fmicb.2011.00054

Velasquez, L. N., Delpino, M. V., Ibanez, A. E., Coria, L. M., Miraglia, M. C., Scian, R., et al. (2012). Brucella abortus induces apoptosis of human T lymphocytes. Microbes Infect. 14, 639-650.

Velikovsky, C. A., Goldbaum, F. A., Cassataro, J., Estein, S., Bowden, R. A., Bruno, L., et al. (2003). Brucella lumazine synthase elicits a mixed Th1-Th2 immune response and reduces infection in mice challenged with Brucella abortus 544 independently of the adjuvant formulation used. Infect. Immun. 71, 5750-5755.

Viadas, C., Rodriguez, M. C., Sangari, F. J., Gorvel, J. P., Garcia-Lobo, J. M., and Lopez-Goni, I. (2010). Transcriptome analysis of the Brucella abortus BvrR/BvrS twocomponent regulatory system. PLoS ONE 5:e10216. doi: 10.1371/ journal.pone.0010216

Vivier, E., Raulet, D. H., Moretta, A., Caligiuri, M. A., Zitvogel, L., Lanier, L. L., et al. (2011). Innate or adaptive immunity? The example of natural killer cells. Science 331, 44-49.

von Bargen, K., Gorvel, J. P., and Salcedo, S. P. (2012). Internal affairs: investigating the Brucella intracellular lifestyle. FEMS Microbiol. Rev. $36,533-562$.

Waag, D. M., England, M. J., Tammariello, R. F., Byrne, W. R., Gibbs, P., Banfield, C. M., et al. (2002). Comparative efficacy and immunogenicity of Q fever chloroform:methanol residue (CMR) and phase I cellular (Q-Vax) vaccines in cynomolgus monkeys challenged by aerosol. Vaccine 20, 2623-2634.

Waddell, S. J., and Butcher, P. D. (2007). Microarray analysis of whole genome expression of intracellular Mycobacterium tuberculosis. Curr. Mol. Med. 7, 287-296.

Wallach, J. C., Ferrero, M. C., Victoria Delpino, M., Fossati, C. A., and Baldi, P. C. (2008). Occupational infection due to Brucella abortus S19 among workers involved in vaccine production in Argentina. Clin. Microbiol. Infect. 14, 805-807.

Wang, Y., Chen, Z., Qiao, F., Ying, T. Yuan, J., Zhong, Z., et al. (2009). Comparative proteomics analyses reveal the virB of B. melitensis affects expression of intracellular survival 
related proteins. PLoS ONE 4:e5368. doi: 10.1371/journal.pone.0005368

Watanabe, K., Tachibana, M., Tanaka, S., Furuoka, H., Horiuchi, M., Suzuki, H., et al. (2008). Heat shock cognate protein 70 contributes to Brucella invasion into trophoblast giant cells that cause infectious abortion. BMC Microbiol. 8:212. doi: 10.1186/1471-2180-8-212

Watarai, M., Makino, S., Fujii, Y., Okamoto, K., and Shirahata, T. (2002). Modulation of Brucellainduced macropinocytosis by lipid rafts mediates intracellular replication. Cell Microbiol. 4, 341-355.

Wattam, A. R., Williams, K. P., Snyder, E. E., Almeida, N. F. Jr., Shukla, M., Dickerman, A. W., et al. (2009). Analysis of ten Brucella genomes reveals evidence for horizontal gene transfer despite a preferred intracellular lifestyle. J. Bacteriol. 191, 3569-3579.

Wehrly, T. D., Chong, A., Virtaneva, K., Sturdevant, D. E., Child, R., Edwards, J. A., et al. (2009). Intracellular biology and virulence determinants of Francisella tularensis revealed by transcriptional profiling inside macrophages. Cell Microbiol. 11, 1128-1150.

Williams, E. (1970). Brucellosis and the British public. Lancet 1, 1220-1222.

Wu, Q., Pei, J., Turse, C., and Ficht, T. A. (2006). Mariner mutagenesis of Brucella melitensis reveals genes with previously uncharacterized roles in virulence and survival. BMC Microbiol. 6:102. doi: 10.1186/ 1471-2180-6-102

Yang, Y., Wang, L., Yin, J., Wang, X., Cheng, S., Lang, X., et al. (2011a). Immunoproteomic analysis of Brucella melitensis and identification of a new immunogenic candidate protein for the development of brucellosis subunit vaccine. Mol. Immunol. 49, 175-184.

Yang, Y., Yin, J., Guo, D., Lang, X., and Wang, X. (2011b). Immunization of mice with recombinant Sadenosyl-L-homocysteine hydrolase protein confers protection against Brucella melitensis infection. FEMS Immunol. Med. Microbiol. 61, 159-167.
Yingst, S., and Hoover, D. L. (2003). $\mathrm{T}$ cell immunity to brucellosis. Crit. Rev. Microbiol. 29, 313-331.

Zhan, Y., and Cheers, C. (1995). Endogenous interleukin-12 is involved in resistance to Brucella abortus infection. Infect. Immun. 63 , 1387-1390.

Zhan, Y., Liu, Z., and Cheers, C. (1996). Tumor necrosis factor alpha and interleukin-12 contribute to resistance to the intracellular bacterium Brucella abortus by different mechanisms. Infect. Immun. 64, 2782-2786.

Zhao, Z., Yan, F., Ji, W., Luo, D., Liu, X., Xing, L., et al. (2011). Identification of immunoreactive proteins of Brucella melitensis by immunoproteomics. Sci. China Life Sci. 54, 880-887.

Zvi, A., Rotem, S., Bar-Haim, E., Cohen, O., and Shafferman, A. (2011). Whole-genome immunoinformatic analysis of F. tularensis: predicted CTL epitopes clustered in hotspots are prone to elicit a T-cell response. PLoS ONE 6:e20050. doi: 10.1371/journal. pone. 0020050

Conflict of Interest Statement: The authors declare that the research was conducted in the absence of any commercial or financial relationships that could be construed as a potential conflict of interest.

Received: 16 October 2012; accepted: 26 April 2013; published online: 16 May 2013.

Citation: Gomez G, Adams LG, RiceFicht A and Ficht TA (2013) HostBrucella interactions and the Brucella genome as tools for subunit antigen discovery and immunization against brucellosis. Front. Cell. Infect. Microbiol. 3:17. doi: 10.3389/fcimb.2013.00017

Copyright (C) 2013 Gomez, Adams, RiceFicht and Ficht. This is an open-access article distributed under the terms of the Creative Commons Attribution License, which permits use, distribution and reproduction in other forums, provided the original authors and source are credited and subject to any copyright notices concerning any third-party graphics etc. 